\title{
New Evidence on the Effects of Job Creation Schemes in Germany - A Matching Approach with Threefold Heterogeneity*
}

\author{
Reinhard Hujer ${ }^{\dagger}$ \\ J.W.Goethe-University, Frankfurt, and IZA, Bonn \\ Marco Caliendo ${ }^{\ddagger}$ \\ J.W.Goethe-University, Frankfurt, and IZA, Bonn \\ Stephan L. Thomsen ${ }^{\S}$ \\ J.W.Goethe-University, Frankfurt \\ This draft: September, 2004
}

\section{Working Paper}

\begin{abstract}
This paper evaluates the effects of job creation schemes on the participating individuals in Germany. The very informative dataset at hand justifies the application of a matching estimator and allows to take account of threefold heterogeneity. The recently developed multiple treatment framework is used to evaluate the effects with respect to regional and individual heterogeneity as well as to differences in the programme sectors. The results show considerable differences with respect to these sources of heterogeneity, but the overall finding is very clear. At the end of our observation period, that is two years after the start of the programmes, participants in job creation schemes have a significantly lower success probability on the labour market in comparison to matched non-participants.
\end{abstract}

Keywords: Job Creation Schemes, Evaluation, Multiple Treatment, Heterogeneity, Matching

JEL Classification: H43, J64, J68, C13, C40

\footnotetext{
*The authors thank Christian Brinkmann, Elke Jahn, Barbara Sianesi, Christopher Zeiss and one anonymous referee for valuable comments. The paper has also benefited from fruitful discussions at the IFS/UCL seminar and the annual meetings of EEA, EALE and Verein für Socialpolitik in 2003. Financial support of the Institute for Employment Research (IAB) within the project 'Effects of Job Creation and Structural Adjustment Schemes' is gratefully acknowledged. All remaining errors are our own.

${ }^{\dagger}$ Reinhard Hujer is Professor of Statistics and Econometrics at the J.W.Goethe-University of Frankfurt and Research Fellow of the IZA, Bonn. Corresponding author: Reinhard Hujer, Department of Economics and Business Administration, Johann Wolfgang Goethe-University, Mertonstr.17, 60054 Frankfurt, Germany, e-mail: hujer@wiwi.uni-frankfurt.de.

${ }_{\ddagger}^{\ddagger}$ Marco Caliendo is Research Assistant at the Institute of Statistics and Econometrics, J.W.Goethe-University of Frankfurt and Research Affiliate of the IZA, Bonn, e-mail: caliendo@wiwi.uni-frankfurt.de.

$\S$ Stephan L. Thomsen is Research Assistant at the Institute of Statistics and Econometrics, J.W.Goethe-University of Frankfurt, e-mail: sthomsen@wiwi.uni-frankfurt.de.
} 


\section{Introduction}

More than ten years after Re-Unification the situation on the labour markets in West and East Germany still differs enormously. This becomes obvious when looking at the unemployment rate in 2001 which was $7.4 \%$ in West Germany and $17.5 \%$ in the East. To overcome this unemployment problem, active labour market policies (ALMP) are regarded as a suitable measure. Therefore it is not surprising that the Federal Employment Agency (FEA) spends significant resources on these measures. The most important ones are vocational training (VT) and job creation schemes (JCS).

Since 1998 the new legal basis for ALMP is the Social Code (SGB III) which has replaced the Work Support Act from 1969. Changes have been made not only in the objectives, like a more intensive focus on problem groups of the labour market, but also in the institutional organisation of labour market policy, leading to decentralisation and more flexibility in the regional allocation of resources to different measures. The local employment offices are now allowed to allocate their budgets relatively freely to different measures to adjust the policies to the situation on the local labour markets. Typically, in situations with great imbalances in the labour market JCS are preferred to training measures, whereas in areas with low unemployment rates hardly any JCS are started. Consequently, JCS play a much bigger role in the East than in the West. Whereas in West Germany the number of entries into VT is four times higher than the number of entries in JCS, this ratio is nearly equal in the East. Up to now, evaluation of JCS has been constricted due to an unsatisfactory data situation. Only a few studies evaluating the microeconomic effects of JCS exist and they all focus on the labour market in East Germany. ${ }^{1}$ Due to this and the small sample sizes in the analyses, the use of the results for general policy conclusions is problematic. But with the introduction of the SGB III a mandatory output evaluation of active labour market policies has been introduced and simultaneously the data situation has improved significantly.

Our paper presents a microeconometric evaluation of JCS in Germany, focussing on the effects on the participating individuals and taking account of several sources of heterogeneity. The estimation is based on a dataset merged from different administrative sources of the FEA. It contains information on all participants in JCS who started their programmes in February 2000, that is 11,376 individuals. The control group consists of 232,399 individuals who met the institutional conditions for participation in JCS in January 2000. The pool of available variables can be differentiated into four categories: Socio-demographic, qualification and career information as well as regional context-variables to take account of the situation on the local labour market.

\footnotetext{
${ }^{1}$ For an overview of these studies see Hujer and Caliendo (2001).
} 
Microeconometric evaluation is generally plagued by the fundamental evaluation problem. That is, one has to make inference about the outcome that would have been observed for participants had they not participated. To overcome this counterfactual situation, identifying assumptions have to be invoked which are generally untestable. The most common assumption in this context is the conditional independence assumption (see e.g. Rubin (1977)), which requires that treatment participation and treatment outcomes are independent conditional on a set of observable characteristics $X$. Since conditioning on all relevant covariates is limited in case of a high dimensional vector $X$ ('curse of dimensionality'), the use of so-called balancing scores is proposed. The exhaustive and informative dataset at hand does justify the application of a matching estimator which exploits CIA but avoids almost any other assumption (Lechner (2002b)). The basic idea underlying it is to replace the counterfactual outcome of the participants by the outcome of a selected group of 'comparable' non-participants. Besides being an intuitively appealing approach and therefore easy to communicate to policy makers, the matching approach avoids functional form assumptions and allows the effects to be different in specific sub-populations (individual heterogeneity). Furthermore in its multiple-treatment version (see Lechner (2001) and Imbens (2000)) it allows to take account of the fact that the evaluated programmes are not homogeneous. Heterogeneity can arise between different programmes like JCS and vocational training (programme heterogeneity) but also in different sectors within the same programme (sectoral heterogeneity). The latter case is important for us, since the sub-parts of the analysed JCS are very diverse regarding their type of occupation (e.g. 'Construction \& Industry' vs. 'Office \& Services'), intensity and duration. As we additionally expect the effects to be different for different strata of the population, e.g. long-term unemployed or young unemployed and finally also regional and gender-specific differences are important, matching seems to be a suitable approach. The remainder of this paper is organised as follows: At first we will give an overview of the institutional setup and instruments of ALMP in Germany. Following that we will describe the dataset and compare the participants in the different sectors of JCS with the non-participants. In section 4 we will outline the general framework for the microeconometric evaluation and present the matching estimator used in this study. In the empirical analysis in the subsequent section we describe the implementation of the estimator, present results and draw some policy conclusions. Finally, we summarise and give an outlook for further research. 


\section{Institutional Setup and Instruments}

The main purpose of this paper is to answer the question if JCS enhance the labour market prospects of the participating individuals. To understand the effects of the different types of programmes and the composition of the participating individuals, we will first review the labour market situation as well as the institutional environment of these programmes.

\subsection{One Country - Two Labour Markets}

A persistent unemployment rate in connection with high expenses for labour market policies characterises the German labour market of the last two decades. However, talking of 'the' German labour market might be misleading due to the special situation of the re-unified Germany after 1990. As a legacy of the former countries, the regional labour markets in western and eastern Germany differ substantially. From 1990 until 1993 the eastern labour market was characterised by an enormous employment reduction from about 9.75 million jobs down to 6.25 million. Besides the structural crisis due to the collapse of the Command Economy, problems arose through difficulties in the adoption of the new economical and behavioural situation. As a consequence, the stock of unemployed increased. However, because of a massive deployment of active labour market and social policy measures, a strong migration and a high number of commuters to the western part, there were only about 1.15 million workers openly unemployed on yearly average. In the years between 1993 and 1995, after this 'Re-Unification-Shock', the eastern labour market was stabilised and recovered slightly. This was mainly driven by a higher demand in the construction business. Since 1996, however, the situation is declining again. While the number of jobs has decreased in the following years, the stock of unemployed has risen up to 1.37 million. Although these figures represent the persistent problems of the eastern labour market, there were also some positive developments, like a good progress in setting-up a more competitive economic environment and modernising the economy. The transformation is processing still, and a quick convergence is not expected. While the eastern labour market suffered from the Re-Unification, the western labour market boomed. The labour force rose both by the immigrants from the eastern part and abroad. Together with a strong increase of employment between 1989 and 1992, the number of unemployed was reduced to 1.80 million. In the years from 1993 to 1997 the western German labour market was affected by an economic slowdown, a delayed effect of the global recession determined by the oil-price shock during and after the Gulf War. In contrast to the eastern part, typical attributes of the economy and the labour market in the western part are a strong export-dependence 
Table 1: The two labour markets in Germany

\begin{tabular}{|c|c|c|c|c|}
\hline \multirow[b]{2}{*}{ Year } & \multicolumn{2}{|c|}{ West } & \multicolumn{2}{|c|}{ East } \\
\hline & 2000 & 2001 & 2000 & 2001 \\
\hline Employment (in million people) ${ }^{1}$ & 32.120 & 32.486 & 6.406 & 6.287 \\
\hline Unemployment (in million people) ${ }^{1}$ & 2.529 & 2.478 & 1.359 & 1.374 \\
\hline Unemployment Rate & $7.8 \%$ & $7.4 \%$ & $17.4 \%$ & $17.5 \%$ \\
\hline Entries into Vocational Training & 337,880 & 261,199 & 213,654 & 188,423 \\
\hline Entries into Job Creation Schemes & 78,684 & 61,890 & 181,395 & 130,147 \\
\hline \multicolumn{5}{|l|}{ Spending on } \\
\hline Passive Labour Market Policies (in bn Euro) & 24.09 & 24.91 & 13.71 & 13.86 \\
\hline Active Labour Market Policies (in bn Euro) & 12.23 & 12.42 & 9.77 & 9.89 \\
\hline Vocational Training (in bn Euro) & 4.06 & 4.19 & 2.75 & 2.80 \\
\hline Job Creation Schemes (in bn Euro) & 1.02 & 0.86 & 2.66 & 2.11 \\
\hline
\end{tabular}

due to production of superior industrial goods and an expanding services-sector. In these years unemployment rose heavily up to 3.02 million in the yearly average. In the end of the 1990s the western German labour market recovered. Between 1997 and 2000 the number of unemployed decreased again but was still persistent on a level around 2.5 million.

In the first half of the year 2000 the German economy had the biggest upswing since the Re-Unification. Despite this, only the western labour market with its strong export-dependence profited. The higher foreign demand did not affect the eastern part because of its minor importance in the export-sector. Furthermore, the continuing structural problems and a reduced demand in the construction sector led to a negative outcome. Since the second half of the year 2000, the German economy experiences a new downswing. Consequently, unemployment rose again in both parts. Even though the figures in table 1 show a reduced number of unemployed and a reduced unemployment rate for western Germany in the yearly average for the year 2001, this is only due to the reduced stock of unemployed in the beginning of 2001 resulting from the upswing in the first half of 2000 .

\subsection{Active Labour Market Policies and Job Creation Schemes}

The unsatisfying situation of the persistently increasing unemployment linked with a strained budget situation led to a re-orientation of labour market policy. Mainly ALMP have become more important during the last years. The reform of the Work Support Act (Arbeitsförderungsgesetz) in 1997/1998 to the Social Code III (Sozialgesetzbuch III) reflects this fact. A higher emphasis on flexibility and decentralisation of the labour market policy should enable a more efficient application of the instruments for the target groups as well as a higher self dependence of the local placement officers. The primary objective of ALMP in Germany is still 
the (re-) integration of unemployed into regular employment. The main purpose of the employment promotion according to the Social Code III is to balance labour demand and supply. Unemployment should be circumvented by an efficient filling of vacancies and the increase of the individual employment chances due to an upgrade of the worker's human capital. Besides those explicit postulations of the legislator for the design of the labour market policy, the evaluation of the success of the instruments is now legally anchored. The analysis of the effects of ALMP is now a focus of labour market research in Germany. The purpose is a more contemporary evaluation of the different instruments, considering aspects like the net-effect on the employment chances for an individual, the identification of macroeconomic effects and cost-benefit analysis.

Spending for ALMP amounts to more than $33.2 \%$ of the total expenditures for labour market policy in West Germany and $41.6 \%$ in East Germany in 2001. The main instruments are VT and subsidised employment. VT consists of several on-the-job and off-the-job measures for unemployed and workers who are threatened by unemployment. The costs for these measures lie at 6.99 billion Euro and 449,622 individuals started training in 2001. On second place regarding the expenses and the number of entries are the JCS with a fiscal volume of 2.97 billion Euro and 192,037 newly promoted individuals in 2001 (Bundesanstalt für Arbeit, 2002). JCS can be promoted if they support activities which are of value for the society and additional in nature. ${ }^{2}$ Furthermore individuals have to be employed whose last chance to stabilise and qualify for later re-integration into regular employment is participation in these schemes. Additional in nature means that the activities could not be executed without the subsidy. Measures with a predominantly commercial purpose have been excluded explicitly up to January 2002; now they can be accomplished with a special permission by the administration board of the local labour office. Participants on JCS are allowed to do a practical training up to $40 \%$ of the time and a VT up to $20 \%$, together no more than $50 \%$ of the programme duration. Priority should be given to projects which enhance the chances for permanent jobs, support structural improvement in social or environmental services or aim at the integration of extremely hard-to-place individuals.

Even though JCS are mainly accomplished by public and social institutions, they could also be organised by the private sector if some special clauses to prevent substitution effects and windfall gains are regarded. Besides the social value and the additional benefit of the activities, participants in JCS in the private sector should be from special target groups of the labour market, e.g. young unemployed without professional training, and get educational supervision during occupation.

\footnotetext{
${ }^{2}$ See $\S \S 260-271$ and 416 in the Social Code III (SGB III) for details.
} 
The legal requirements for individuals to enter JCS are relaxed by the SGB III amendment (Job-Aqtiv-Gesetz) in January 2002. Before that time, potential participants had to be long-term unemployed (more than one year) or unemployed for at least six months within the last twelve months. Additionally they had to fulfil the conditions for the entitlement of unemployment compensation. ${ }^{3}$ In addition, the local placement officers were allowed to place up to five percent of the allocated individuals who do not meet these conditions (Five-PercentQuota). Further exceptions are made for young unemployed (under 25 years) without professional training, short-term unemployed (with at least three months of unemployment) placed as tutors, and disabled who could be stabilised or qualified.

With the 2002 amendment, all unemployed individuals can enter a JCS independent of the preceding unemployment duration, but with the restriction that JCS is the only opportunity for occupation. In addition, the Five-Percent-Quota was augmented up to ten percent. The subsidy is normally paid for 12 months, but can be extended up to 24 or even 36 months, if it is followed by regular employment. Even though JCS should be co-financed measures where between $30 \%$ and $75 \%$ of the costs are subsidies by the FEA and the rest is paid by the supporting institution (public or private legal entities, mainly municipalities), exceptions can be made in the direction of a higher subsidy-quota (up to $100 \%$ ).

Participation in JCS results from placement by the local labour office. Unemployed individuals who cannot be integrated into regular employment or do not fit the conditions for another instrument of active labour market policy are offered a place in JCS. JCS can be implemented in nine different sectors. Since the definition of this sector-structure comes from the mid 1980s, the changes due to the Re-Unification, the new orientation of the labour market policy and the labour environment in the 1990s and 2000s are not regarded. In our study we focus on the main four sectors 'Agriculture', 'Construction \& Industry', 'Office \& Services' and 'Community Services'. The rest is summarised in the sector 'Other'. In the placement process the unemployed individual is offered a specific job in one measure where a place is available and which fits his characteristics. The placement officer can cancel the treatment before the regular end if the participating individual can be placed in the first labour market. If an unemployed rejects the offer of a JCS or if a participant denies a career counselling by the

\footnotetext{
${ }^{3}$ There are two kinds of unemployment compensation in Germany. The first kind are unemployment benefits (UB) that are paid dependent on the preceding duration of employment, the age and if the individual has children. To get UB, an individual must register unemployed at the local labour office, seek for a regular occupation and have worked in regular employment before. The UB amounts to $60 \%$ (67\%) of the net-wage of the last occupation for unemployed without (with) children. The longest possible UB entitlement is 32 months. After expiration of the UB entitlement, unemployed can gain unemployment assistance (UA) if they are in need of further promotion. In analogy to the UB entitlement, the UA differs dependent on having or not having children. The amount of UA for persons without (with) children is $53 \%(57 \%)$ of the last net-wage. The UA is paid for one year at maximum, but can be prolonged by case-wise revision. For every following year the grants are paid on a p.a. $3 \%$ reduced last net-income basis. Participation in a job creation scheme prolongs the entitlement for UB in the same way as regular employment.
} 
placement officer, the labour office can stop the unemployment benefits for up to twelve weeks. However, due to legal restrictions the use of this penalty is negligible.

\section{Dataset and Descriptive Analysis}

Data Base The empirical analysis is based on a data set matched from several administrative data sources of the FEA. The central source of information used is a prototype version of the programme participants master data set (Maßnahmeteilnehmergrunddatei, MTG). This data set includes information on all participants in subsidised employment in Germany. The attributes are taken from three separate data sources of the FEA, the job-seekers data base (BewA), an adjusted version of this source for statistical purposes (ST4) and the participants' data base of subsidised employment (ST11TN). The MTG contains a large number of attributes to describe several individual aspects that can be split into four classes: socio-demographic and qualification information, labour market history and particular programme information. To describe the regional context we used the employment offices' data base (ST1VOR). Table 2 gives detailed information of the data sources and the included attributes.

Table 2: Data Sources and Attributes

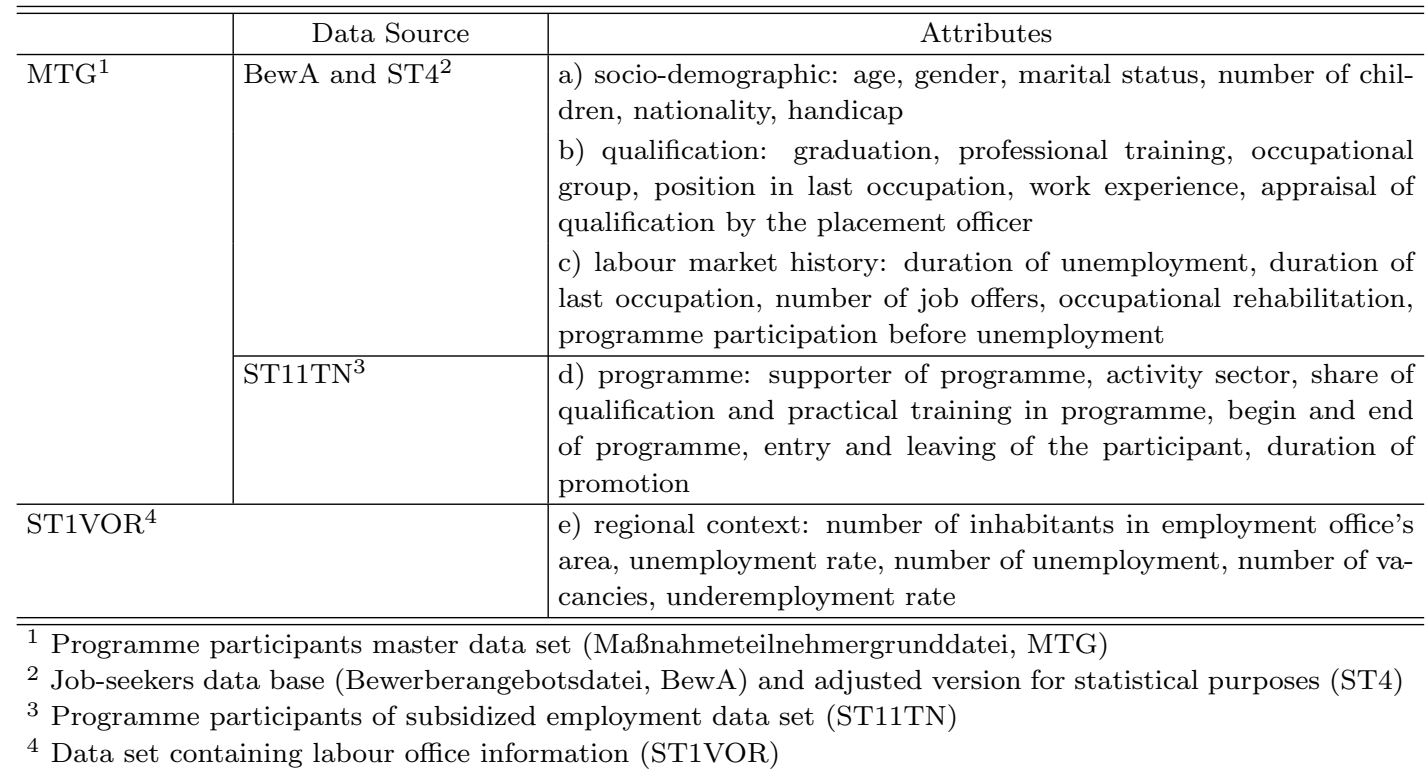

Our analysis builds on a sample from the MTG of all 11,376 participants who entered JCS in February 2000.

Only the first programme participation is evaluated, any participation in later programmes, e.g. VT, is viewed 
as an outcome of the first treatment. ${ }^{4}$ The comparison group consists of 232,399 individuals who met the institutional conditions for participation in JCS in January 2000, but did not enter those schemes in the observation period, which is mainly caused by the limited availability of slots in JCS. The sample was drawn from the job-seekers data base and the attributes from the ST4 were added. The unemployment status of all individuals was tracked until March 2002.

Descriptive Analysis Tables A.1 and A.2 in the appendix show selected descriptive statistics of the participants in the five programme sectors and for the group of non-participants measured in January 2000. Heterogeneity with respect to programme and individual characteristics becomes obvious by these statistics. For instance, the average duration of unemployment before programme participation varies in the five sectors and also between East and West Germany. Individuals who participate in programmes in the 'Community Services' sector have the shortest duration of unemployment in West Germany with 53.1 weeks on average, in East Germany these are the participants in the 'Construction \& Industry' sector (53.1 weeks). In both regions the longest duration of unemployment are found for participants in 'Agriculture' (West: 66.8, East: 64.1 weeks). The duration of unemployment of the non-participants is notably longer than for the participants. This might be due to a higher willingness of the participants or reflect the fact that there is only a limited number of places in programmes available. Clearly, one task of the matching approach is to find comparable non-participants in terms of unemployment duration. Besides the varying average duration of unemployment before programme participation also the programme duration varies. Longest promotion is given in the services' sectors ('Office \& Services', 'Community Services'), where particularly higher qualified individuals work.

The placement of participants seems to be oriented on the individual skills. Whereas the biggest group of participants in 'Agriculture' and 'Construction \& Industry' comes from manufacturing, the services sectors are dominated by service professions. The qualification level of participants is very low on average. Apart from the services in East and West, the quota of individuals without professional training and without CSE is higher than in the group of non-participants. Consequently, the group of non-skilled workers as a professional rank is, apart from the services sectors, larger in the participants' group compared to the non-participants.

Furthermore, there are interesting regional differences in JCS. The average age of participants is about six to nine years higher in East Germany than in West Germany. Women are higher represented in the eastern part. Here, particularly in 'Community Services' and 'Office \& Services' there are $81.4 \%$ and $76.3 \%$ female

\footnotetext{
${ }^{4}$ See Lechner and Miquel (2001) for an approach to evaluate dynamic programme sequences.
} 
participants. In contrast, the proportion of women in West Germany in 'Agriculture' and 'Construction \& Industry' amounts only to $7.4 \%$ and $9.4 \%$.

The underemployment rate in the labour office district can be interpreted as an indicator for the condition of the regional labour market. ${ }^{5}$ The figures portray the special situation of the labour market in Germany (see above). While the majority of the labour office districts in West Germany has an underemployment rate between 7.5\% to $15.0 \%$, for East Germany it lies between $22.5 \%$ to $30 \%$.

\section{Methodology}

\subsection{General Framework}

The standard model in the microeconometric evaluation literature is the potential outcome approach or Roy(1951)Rubin(1974)-model. In this model an individual can choose between two states, e.g. either participating in a certain labour market programme or not. The individual has then two potential outcomes, where $Y^{1}$ is a situation with treatment and $Y^{0}$ is a situation without treatment. If we use $D \in\{0,1\}$ as a binary treatment indicator, the actually observed outcome for any individual $i$ can be written as: $Y_{i}=Y_{i}^{1} \cdot D+(1-D) \cdot Y_{i}^{0}$. Since we cannot observe the same individual in both states at the same time, we have to to deal with a counterfactual situation and the so-called fundamental evaluation problem. The parameter which receives most attention in the evaluation literature is the 'average treatment effect on the treated' (ATET), that is: $E\left[Y^{1}-Y^{0} \mid D=1\right]$. Estimating this effect requires to make inference about the outcome that would have been observed for participants had they not participated. In social experiments where eligible persons are randomly denied access to the programme, the randomised-out control group provides a direct estimate of $E\left[Y^{0} \mid D=1\right]$, whereas in non-experimental studies no such direct estimate is available (Smith and Todd (2004)).

When evaluating the active labour market policies of countries, researchers are usually not confronted with only one homogeneous programme but with a variety of different ones, e.g. wage subsidies, training programmes or JCS. Even when looking at one specific programme, like in our case JCS, the sub-parts of the programme may be very heterogeneous regarding the type of occupation, intensity, duration, etc. To account for programme heterogeneity, the standard evaluation framework has been extended by Imbens (2000) and Lechner (2001). The multiple treatment framework considers the case of $(M+1)$ mutually different and exclusive treatments

\footnotetext{
force.

${ }^{5}$ The underemployment rate is defined as the sum of openly unemployed and programme participants in relation to the labour
} 
instead of just two. For every individual only one component of the $M+1$ different outcomes $\left\{Y^{0}, Y^{1}, \ldots, Y^{M}\right\}$ can be observed, leaving $M$ as counterfactuals. Participation in treatment $m$ is indicated by $S \in\{0,1, \ldots, M\}$. An important concept in this framework is the stable unit-treatment value assumption (SUTVA) ${ }^{6}$, which requires that the potential outcomes of an individual depend on his own participation only and not on the treatment status of other individuals. Furthermore, whether an individual participates or not does not depend on the participation decision of other individuals. The latter requirement excludes peer-effects, whereas the first one excludes cross-effects or general equilibrium effects (Sianesi (2004)).

The interest lies in the causal effect of one treatment relative to another treatment on an outcome variable. Even though Lechner (2001) defines several interesting parameters, we will focus on the ATET. ${ }^{7}$ In the multipletreatment notation that effect is defined as a pair-wise comparison of the effects of the treatments $m$ and $l$ for an individual randomly drawn of participants in $m$ only:

$$
\theta_{0}^{m l}=E\left(Y^{m}-Y^{l} \mid S=m\right)=E\left(Y^{m} \mid S=m\right)-E\left(Y^{l} \mid S=m\right)
$$

It is worth noting that this treatment effect is not symmetric if the participants in $m$ and $l$ differ in a non-random fashion which is related to the outcomes. In the presented framework the causal treatment effect is generally not identified. To overcome the counterfactual situation identifying assumptions have to be invoked which are generally untestable. The most common assumption in this context is the conditional independence assumption (see e.g. Rubin (1977)), which requires that treatment participation and treatment outcomes are independent conditional on a set of observable characteristics $X .{ }^{8}$ Imbens (2000) and Lechner (2001) consider identification under CIA in the multiple treatment framework and formalise it in the following way:

$$
Y^{0}, Y^{1}, \ldots, Y^{M} \amalg S \mid X=x, \forall x \in \chi \cdot^{9}
$$

That is, all potential treatment outcomes are independent of the assignment mechanism for any given value of a vector of attributes, $X$, in an attribute space, $\chi$ (Lechner (2002a)). For this assumption to be fulfilled, the researcher has to observe all characteristics that jointly influence the participation decision and the outcomes and therefore its plausibility depends on the dataset at hand. Assumption (2) is too restrictive if the parameter of interest is the mean effect of treatment on the treated, since in that case conditional mean independence

\footnotetext{
${ }^{6}$ See Rubin (1980) or Holland (1986) for a further discussion of this concept.

${ }^{7}$ Other parameters of interest are e.g. the average treatment effect of treatment $m$ relative to treatment $l$ for persons randomly drawn from the population or randomly drawn from participants in either $m$ or $l$.

${ }^{8}$ These variables are unaffected by treatment and called attributes by Holland (1986).

${ }^{9}$ This identifying assumption is termed 'strong unconfoundness' by Imbens (2000).
} 
suffices (Smith and Todd (2004)). However, Lechner (2002b) argues that the CIA has the virtue of identifying the mean effects for all transformations of the outcome variables and furthermore it will be difficult to argue why conditional mean independence should hold and CIA might still be violated in empirical studies.

Conditioning on all relevant covariates is, however, limited in case of a high dimensional vector $X$ ('curse of dimensionality'). Rosenbaum and Rubin (1983) show for the single treatment case that it is not necessary to condition on $X$, but instead it is sufficient to use so-called balancing scores, i.e. functions of the relevant observed covariates. A balancing score $b(X)$ is a function of $X$, such that conditional on it, the characteristics $X$ are balanced across the groups, i.e. $S \amalg X \mid b(X)$.

The propensity score $P^{m}(X)$, i.e. the probability of participating in a programme, is one possible balancing score. It summarises the information of the observed covariates into a single index function. Lechner (2001) shows that a generalisation of the balancing score property holds for the case of multiple treatments as well:

$$
Y^{0}, Y^{1}, \ldots, Y^{M} \amalg S\left|X=x \quad \rightarrow \quad Y^{0}, Y^{1}, \ldots, Y^{M} \amalg S\right| b(X)=b(x), \forall x \in \chi^{10}
$$

Given that, the ATET (here: effect of treatment $m$ compared with treatment $l$ on the participants in treatment $m)$ can be written as (Lechner (2002a)):

$$
\theta_{0}^{m l}=E\left(Y^{m} \mid S=m\right)-E_{P l \mid m l}\left[E\left\{Y^{l} \mid P^{l \mid m l}(X), S=l\right\} \mid S=m\right],
$$

where: $P^{l \mid m l}(x)=P^{l \mid m l}(S=l \mid S \in l, m, X=x)=\frac{P^{l}(x)}{P^{l}(x)+P^{m}(x)}$.

The marginal probability of treatment $j$ conditional on $X$ is denoted as $P(S=j \mid X=x)=P^{j}(x)$. $\theta_{0}^{m l}$ is identified and the dimension of the estimation problem is reduced to one. It is interesting to note that if $P^{l \mid m l}$ is modelled directly, no information from subsamples other than those containing participants in $m$ and $l$ is needed for the identification of (4) and we are basically back in the binary treatment framework. Since the choice probabilities in (4) will not be known a-priori, they have to be replaced by an estimate, e.g. a probit model. If all values of $m$ and $l$ are of interest, the whole sample is needed for identification. In that case either the binary conditional probabilities can be estimated or a structural approach can be used where a complete

\footnotetext{
${ }^{10}$ See Appendix A in Lechner (2001) for a proof.
} 
choice problem is formulated in one model and estimated on the full sample, e.g. with a multinomial probit model.

\subsection{A Matching Estimator for the Evaluation Problem at Hand}

Once the score is available, an estimator is needed that exploits CIA but avoids almost any other assumption (Lechner $(2002 \mathrm{~b})$ ). One popular choice in this context is the matching estimator. ${ }^{11}$ The basic idea underlying the matching approach on balancing scores is to replace the second term on the right hand side of equation (1), that is $E\left(Y^{l} \mid S=m\right)$, by a selected group of participants in $l$ that has the same distribution for the balancing score as the group of participants in $m$. Given the balancing property, the distribution of $X$ will also be balanced in the two samples. Besides being an intuitively appealing approach and therefore easy to communicate to policy makers, the matching approach avoids functional form assumptions and allows the effects to be different in specific sub-populations (individual heterogeneity). Furthermore it allows to take account of the fact that the evaluated programme sectors are not homogeneous (programme heterogeneity, Lechner (2002b)).

When discussing the suitable approach to be used in this application, we have to bear several things in mind. First, the descriptive statistics have shown that the participants in both regions and in the different measures are very heterogeneous. Therefore the possible influence of regional, individual and sectoral heterogeneity has to be considered. Second, as has been described in the previous section, the decision process on which programme to choose is a binary one, making a multinomial approach unappropriate. Furthermore, the policy-relevant question to answer is, if - in order to enhance their employment prospects - unemployed in February 2000 should be placed in a job creation scheme or not. In the latter case individuals would have to seek a job without the additional benefit of the programme. Finally, the group of non-participants is between twenty and fourty times larger than the group of participants in any sub-part of the programme.

Effects in Sub-Populations Therefore we decided to estimate the effects of the different programmes in the different sub-populations relative to non-participation only. Since we are just interested in the pair-wise comparison of the various kinds of treatments, assumption (2) can be relaxed, requiring conditional independence to hold only for the sub-population receiving either treatment $m$ or treatment $l$ (see Lechner (2001) and Sianesi

\footnotetext{
${ }^{11}$ Recent applications of matching estimation can be found in Gerfin and Lechner (2002), Sianesi (2004) or Brodaty, Crepon, and Fougere (2001) for Switzerland, Sweden and France. More methodological aspects are discussed e.g. in Heckman, Ichimura, and Todd (1998), Smith and Todd (2004) and Blundell and Costa Dias (2000).
} 
(2004)), where treatment $l$ is our non-participation state and $m \in\{1, \ldots, 5\}^{12}$ :

$$
\begin{array}{r}
\theta_{0}^{m l}=E\left(Y^{m}-Y^{l} \mid S=m\right)=E\left(Y^{m} \mid S=m\right)-E\left(Y^{l} \mid S=m\right) \\
\text { for } m=1, \ldots, 5 .
\end{array}
$$

Estimating the effects separately for men and women in East and West Germany for the different sectors $m$ accounts for regional, gender-specific and sectoral heterogeneity. To allow additionally for individual heterogeneity we also estimate the effects for various strata of the population. This stratification is orientated by the target groups of JCS.

Since young unemployed without profession are one target group, one obvious criterion to look at is the age of participants. Besides that, JCS should also stabilise 'older' unemployed with bad labour market prospects, so we examine the effects in three different age classes $(<25,25-50,>50$ years $)$ :

$$
\begin{array}{r}
\theta_{0 a}^{m l}=E\left(Y^{m}-Y^{l} \mid S=m\right)=E\left(Y^{m} \mid S=m\right)-E\left(Y^{l} \mid S=m\right) \\
\text { for } m=1, \ldots, 5 \text { and } a=A_{g e_{<25}, A e_{25-50}, A g e_{>50} .}
\end{array}
$$

Another particular target group are long-term unemployed. Therefore our second criterion is the duration of previous unemployment (again in three classes: $<13,13-52,>52$ weeks):

$$
\begin{array}{r}
\theta_{0 u}^{m l}=E\left(Y^{m}-Y^{l} \mid S=m\right)=E\left(Y^{m} \mid S=m\right)-E\left(Y^{l} \mid S=m\right) \\
\text { for } m=1, \ldots, 5 \text { and } u=U N_{<13}, U N_{13-52}, U N_{>52} .
\end{array}
$$

Matching Algorithm Several different matching estimators have been discussed (see e.g. Heckman, Ichimura, Smith, and Todd (1998) or Smith and Todd (2004)) and the exact protocol of the one used in that application can be found in Table A.4. The choice of the matching method involves a trade-off between matching quality and variance. First, one has to decide on how many non-treated individuals to match to a single treated individual. Nearest-neighbour (NN) matching only uses the participant and its closest neighbour. Therefore it minimises the bias but might also involve an efficiency loss, since a large number of close neigbours are disregarded. Kernel-based matching on the other hand uses more non-participants for each participant thereby reducing the variance but possibly increasing the bias. Finally, using the same non-treated individual more than once (NN matching with replacement) can possibly improve the matching quality, but increases the variance. ${ }^{13}$ Since we

\footnotetext{
${ }^{12}$ The five sectors of the programme are: 'Agriculture', 'Construction \& Industry', 'Office \& Services', 'Community Services' and 'Other'.

${ }^{13}$ Following Lechner (2001), the variance of the treatment effect at time $t$ is calculated by assuming independent observations, fixed weights, homoscedasticity of the outcome variable within the treatment and within the control group and that the outcome
} 
have a large sample of participants and an even larger sample of non-participants, we use NN matching without replacement for our study. ${ }^{14}$

Common Support A further requirement besides independence is the common support condition. It requires that all individuals in that subspace actually can participate in all states:

$$
0<P(S=m \mid X=x)<1, \forall m=0, \ldots, M, \forall x \in \chi
$$

If there are regions where the support of $X$ does not overlap for the different groups, matching is only justified when performed over the common support region and the estimated treatment effect must then be redefined as the treatment impact for programme participants whose probabilities lie within the overlapping support region (Smith and Todd (2004)).

Match Quality Since we do not condition on all covariates but on the propensity score, it has to be checked if the matching procedure is able to balance the distribution of the relevant variables in the control and treatment groups. One suitable indicator to assess the distance in the marginal distributions of these characteristics is the standardised bias suggested by Rosenbaum and Rubin (1985). For each covariate $X$ it is defined as the difference of the sample means in the treated and matched control subsamples as a percentage of the square root of the average of the sample variances in both groups (Sianesi (2004)). ${ }^{15}$

When to compare An important decision which has to be made in the empirical analysis is when to measure the effects. The major goal is to ensure that participants and non-participants are compared in the same economic environment and the same individual lifecycle position. One possible problem which has to be taken into account is the occurrence of locking-in effects. The literature is dominated by two approaches, either comparing the individuals from the begin of the programme or after the end of the programme. The latter alternative implies that the outcome of participants who finish the programme in October 2000 and re-enter the labour market in November 2000, is compared with matched non-participants in November 2000. This approach is problematic if the exits are spread over a longer time period because possibly very different economic $\overline{\text { does not depend on the propensity score: } \operatorname{Var}\left(\hat{\theta}_{N}^{m l}\right)}=\left(N^{m}\right)^{-1} \cdot \operatorname{Var}\left(Y^{m} \mid S=m\right)+\left[\left(\Sigma_{i \in l}\left(w_{i}^{m}\right)^{2}\right) /\left(\left(N^{m}\right)^{2}\right)\right] \cdot \operatorname{Var}\left(Y^{l} \mid S=l\right)$, where $N^{m}$ is the number of matched treated in programme $m$ and $w_{i}$ is the number of times control $i$ has been used, where $\Sigma_{i \in l}\left(w_{i}^{m}\right)=1$. The left term can be re-written as: $\left(N^{m}\right)^{-1} \cdot\left[\left(\Sigma_{i \in l}\left(w_{i}^{m}\right)^{2}\right) /\left(N^{m}\right)\right] \cdot \operatorname{Var}\left(Y^{l} \mid S=l\right)$. If no unit is matched more than once, the formula conincides with the 'usual' variance formula.

${ }^{14}$ The sensitivity of the results has been tested with respect to matching with replacement, but no significant differences could be found.

${ }^{15}$ That is $100 \cdot\left(\bar{X}_{1}-\bar{X}_{0 M}\right) /\left\{\sqrt{\left(V_{1}(X)+V_{0 M}(X)\right) / 2}\right\}$, where $X_{1}\left(V_{1}\right)$ is the mean (variance) in the treated group and $X_{O M}$ $\left(\left(V_{0 M}\right)\right.$ is the mean in the matched control group. 
situations are compared. A further problem which arises with this approach is that it entails an endogeneity problem (Gerfin and Lechner (2002)). A second approach which is predominant in the recent literature (see e.g. Sianesi (2004) or Gerfin and Lechner (2002)) and which is also used here, measures the effects from the begin of the programme. Since one entry condition for the participants is that they had to be unemployed (at least) in January 2000 , the control group has been chosen in the way that they fulfill this condition, too. ${ }^{16}$ So basically, the policy-relevant question is if the placement officer should place an unemployed individual in February 2000 in a JCS or not. Therefore comparing both groups from the begin of the programme seems to be a reasonable approach.

Locking-in Effect What should be kept in mind is the possible occurrence of locking-in effects for the group of participants. Since they are involved in the programme, they do not have the same time to search for a new job as non-participants. Following van Ours (2002), the net effect of a programme consists of two opposite effects. First, the increased employment probability through the programme and second, the reduced search intensity. Since both effects cannot be disentangled, we only observe the net effect and have to take this into account when interpreting the results. As to the fall in the search intensity we should expect an initial negative effect from any kind of participation in a programme. However, since we observe the outcome of the individuals until two years after the begin of the programme a successful programme should overcompensate for this initial fall.

\section{Empirical Analysis}

\subsection{Implementation}

Plausibility of CIA in our Context Before starting with the estimation of the propensity scores, we have to consider briefly the plausibility of the CIA in our context. As already noted for the CIA to be fulfilled we need to condition on all variables that jointly influence the participation decision and the outcome variable. The used dataset contains four different categories of variables. First, socio-demographic variables like age, gender, marital status, number of children, etc. Second, information about the qualificational background, e.g. education, occupational group, professional rank and work experience. Third, the dataset also includes, and that is most important since previous studies have emphasised the importance of the labour market history, career

\footnotetext{
${ }^{16}$ In fact, the average duration of unemployment in January 2000 is 72.31 (65.93) weeks for the non-participants and between 53.13 (53.10) and 66.79 (64.11) weeks for the participants in the different sectors in West (East) Germany.
} 
details. In this category, we have information about the duration of the last employment and unemployment which leaves us on average with a labour market history of two years before the programme started. Furthermore, this category also contains information about placement restraints and the number of placement propositions. Finally, to take account of the regional labour market situation, the fourth category includes the size of the labour office district and the underemployment rate of that region in the fourth quarter of 1999. Given this informative dataset, we argue henceforth that the CIA holds.

Propensity Scores We estimated binary probits for every treatment group $m \in\{1, \ldots, 5\}$ against the group of non-participants. To account for regional heterogeneity and to allow for gender-specific interaction effects, the probits are estimated separately for men and women in East and West Germany, leaving us with 18 probit estimations. ${ }^{17}$ The choice of the variables that are selected in the estimation are based on score tests. The results can be found in tables A.5, A.6, A.7 and A.8 in the appendix.

It is worth noting that the parameters of the choice estimations not only diverge with respect to regional differences but also with respect to gender-specific and programme sector-specific aspects. For example, married men $(-0.1189)$ and women $(-0.2047)$ in West Germany have a lower probability to participate in a programme in the sector 'Community Services' than men (0.2496) and women (0.0696) in East Germany. A good example for the programme-specific differences is the influence of age for the participation decision. Whereas age has a negative impact on the probability for men in West Germany to join the sector 'Construction \& Industry' $(-0.0588)$, it has a positive impact for joining 'Office \& Services' $(0.1187)$. There is a strong tendency for men with health restrictions to take up a programme in the 'Office \& Services' sector. People with higher qualifications (college or university degree, polytechnic or technical school) tend to go in the sectors 'Office \& Services' or 'Community Services'. It is quite interesting to note that in comparison to people without completed professional training, all other individuals have a negative probability to go in the 'Agriculture' sector. The influence of the former profession is straightforward in most of the sub-groups. Individuals who have been in manufacturing have a higher probability of ending up in the sectors 'Agriculture' or 'Construction \& Industry'. In contrast to this, individuals with service professions tend to go either in the sector 'Office \& Services' or 'Community Services'. An exception can be found in East Germany where men coming from

\footnotetext{
${ }^{17}$ Since the number of participating women in West Germany in the sectors 'Agriculture' and 'Construction \& Industry' has been too small, they have been excluded from the analysis. We also estimated the propensity scores for the two regions with dummy variables for the sex. However, using the results of these 10 probits ignores possible gender-specific interaction effects and the fact that the coefficients in the estimation differ in their significance and magnitude between men and women. This leads to a worse matching quality in the sense that the balancing of covariates after matching is reduced, i.e. the standardised bias is higher.
} 
Table 3: Loss of observations due to the common support requirement (in \%)*

\begin{tabular}{|c|c|c|c|c|c|c|c|c|}
\hline & \multicolumn{4}{|c|}{ West Germany } & \multicolumn{4}{|c|}{ East Germany } \\
\hline & \multicolumn{2}{|r|}{ Men } & \multicolumn{2}{|c|}{ Women } & \multicolumn{2}{|r|}{ Men } & \multicolumn{2}{|c|}{ Women } \\
\hline & Part. & Non-Part. & Part. & Non-Part. & Part. & Non-Part. & Part. & Non-Part. \\
\hline Agriculture & 0.74 & 7.32 & - & - & 0.11 & 0.61 & 0.11 & 2.46 \\
\hline Construction \& Industry & 0.25 & 17.22 & - & - & 0.00 & 9.61 & 0.00 & 10.31 \\
\hline Office \& Services & 1.47 & 20.14 & 0.94 & 13.31 & 0.50 & 29.89 & 0.15 & 3.88 \\
\hline Social Services & 0.57 & 4.83 & 0.37 & 4.41 & 0.24 & 5.61 & 0.11 & 0.65 \\
\hline Other & 0.12 & 2.80 & 0.00 & 6.74 & 0.10 & 0.67 & 0.14 & 2.66 \\
\hline
\end{tabular}

* The total number of participants lost is 24 .

- Groups with less than 50 observations are omitted.

technical professions are more likely to participate in 'Office \& Services' compared to men coming from service professions. Other characteristics like the number of placement propositions show the same trend for all groups and sectors. In general the people with a higher number of placement propositions have a higher probability to join JCS. The list of examples is long, but for the sake of brevity we stop commenting here. The interested reader is referred to the tables in the appendix.

Common Support The estimated propensity scores are used for our matching procedure. To ensure the common support requirement we had to delete some observations across the different subsamples. Since we estimated pairwise effects between the five different treatments vs. non-participation, we used the criterion that all estimated probabilities in the particular subgroups are smaller than the smallest maximum and larger than the largest minimum. ${ }^{18}$ The number of observations lost due to this requirement can be found in table 3 . It can be seen that the number of participants lost in the specific subgroups is fairly small. The maximum is $1.47 \%$ for men in West Germany who are in the 'Office \& Services' sector, whereas in all other subgroups the loss is below 1\%. For the non-participants, however, the losses lie between $0.61 \%$ and $29.89 \%$. But since we had a much larger group of non-participants and furthermore we are interested in the ATET only, this loss is negligible.

Matching Quality Since we do not condition on all covariates but on the propensity score, we check the ability of the matching procedure to balance the relevant covariates by comparing the absolute bias between the respective participating and non-participating groups before and after the matching took place. The results can be found in table 4 . The bias before matching lies between $10 \%$ and $20 \%$ and a significant reduction can be achieved for all subgroups so that the bias after matching is below $4 \%$ for ten out of eighteen subgroups. For

\footnotetext{
${ }^{18}$ Several other common support conditions have been suggested, e.g. Smith and Todd (2004) propose to use a 'trimming level' $q$. That is, not only observations with zero density but also those where the densities are positive but very low (below $q$ ) are excluded from the analysis.
} 
Table 4: Matching quality (Standardised bias)*

\begin{tabular}{lcccccc}
\hline \hline \multirow{2}{*}{ Men West } & $\begin{array}{c}\text { abs. bias in } \\
\%\end{array}$ & Agriculture & $\begin{array}{c}\text { Construction } \\
\text { \& Industry }\end{array}$ & $\begin{array}{c}\text { Office \& } \\
\text { Services }\end{array}$ & $\begin{array}{c}\text { Social } \\
\text { Services }\end{array}$ & Other \\
& before & 15.00 & 15.32 & 20.30 & 15.93 & 12.80 \\
& after & 4.23 & 3.45 & 6.20 & 5.33 & 2.85 \\
\hline \multirow{2}{*}{ Women West } & before & - & - & 17.68 & 16.02 & 14.80 \\
& after & - & - & 5.86 & 3.19 & 5.54 \\
\hline \multirow{2}{*}{ Men East } & before & 14.50 & 13.68 & 20.31 & 13.16 & 11.64 \\
& after & 2.99 & 3.15 & 5.77 & 4.75 & 2.36 \\
\hline \multirow{2}{*}{ Women East } & before & 13.93 & 16.99 & 17.48 & 11.68 & 10.27 \\
& after & 2.65 & 6.56 & 2.44 & 1.87 & 2.23 \\
\hline \hline
\end{tabular}

* The standardised bias is defined as: $100 \cdot\left(\bar{X}_{1}-\bar{X}_{0 M}\right) /\left\{\sqrt{\left(V_{1}(X)+V_{0 M}(X)\right) / 2}\right\}$. The 'total' bias has been estimated as an unweighted average of all covariates.

the rest of the subgroups the bias after matching is between $4.23 \%$ and $6.20 \%$ (for men in West Germany in the sector 'Office \& Services'). Given the fact that the bias for the latter group has been $20.3 \%$ this is acceptable. It should be clear that matching balances the distribution of observed characteristics only. In fact, CIA assumes that a selection only occurs on these variables. To test the sensitivity of our results with respect to unobserved influences, we will use an approach suggested by Rosenbaum (2002) after the presentation of the results in the next section.

\subsection{Results}

Outcome Variable One major element of programme evaluation is the choice of a suitable outcome variable. Since one goal of JCS in Germany is the re-integration of unemployed in the first labour market, one obvious choice would be the employment status of the individuals. ${ }^{19}$ However, our dataset does not contain the employment status but it allows us to monitor if the individual is registered as a job-seeker or not. This information is divided into three categories. Individuals may be either registered unemployed (category 1), registered as job-seeker but not unemployed (category 2) or not registered as job-seeker (category 3). Since these formal definitions are not very enlightening, they are best explained with some examples. The most straightforward category and the only one which does not need an additional explanation is the first one, i.e. the one which contains all unemployed people. The second category contains all people who are registered as job-seekers but not as unemployed. Good examples for this category are individuals in temporary employment, regular employed who are looking for an alternative job and also individuals participating in an active labour market programme. Finally, the last category (not registered as job seeker) includes individuals in regular employment.

\footnotetext{
${ }^{19}$ Other goals besides that, e.g. social stabilisation, cannot be evaluated here.
} 
Unfortunately, this category might also contain individuals on maternity leave, who have just retired or left the labour force for other reasons. Table 5 summarises the available information.

Table 5: Lower and upper bounds for the outcome variable

\begin{tabular}{|c|c|c|c|}
\hline \multirow[t]{2}{*}{ Status } & \multirow[t]{2}{*}{ Definition } & \multicolumn{2}{|c|}{ Rating } \\
\hline & & Lower Bound & Upper Bound \\
\hline $\begin{array}{l}\text { Registered unemployed } \\
\text { (category 1) }\end{array}$ & $\begin{array}{l}\text { Individuals who are registered as unemployed at the } \\
\text { labour office }\end{array}$ & \multirow[t]{2}{*}{ Failure } & Failure \\
\hline $\begin{array}{l}\text { Registered as job-see- } \\
\text { king, but not unemplo- } \\
\text { yed (category } 2 \text { ) }\end{array}$ & $\begin{array}{l}\text { Individuals who are registered as job-seeking at the } \\
\text { labour office, but not as unemployed. These are for } \\
\text { example employees in regular employment, who are } \\
\text { threatened by unemployment or seeking another oc- } \\
\text { cupation, participants in active labour market policy } \\
\text { programmes. }\end{array}$ & & \multirow[t]{2}{*}{ Success } \\
\hline $\begin{array}{l}\text { Not registered as job- } \\
\text { seeker (category } 3 \text { ) }\end{array}$ & $\begin{array}{l}\text { Persons who are not registered as job-seeking at the } \\
\text { labour office, for example individuals in regular em- } \\
\text { ployment, maternity leave or retirement. }\end{array}$ & Success & \\
\hline
\end{tabular}

Especially the second category is hard to assess, as an individual in that category might on the one hand be regularly employed or on the other hand participate in another labour market programme. Assessing people in that category as a failure might therefore lead to an underestimation of the treatment effect, whereas an assessment of them as a success would lead to an overestimation. To overcome this problem we estimate lower and upper bounds for the true treatment effect (success probability on the labour market). People in the first category are measured as a failure in both scenarios. Measuring people in the third category as a success of the programme in terms of re-employment is problematic since people in that category might also have left the labour force. If people are discouraged for further job-seeking after participation and leave the labour force, this outcome does not equal integration into regular employment. However, following budgetary considerations individuals in the third category are a success, since they do not get benefits from the FEA anymore and therefore lessen the financial burden of the FEA. Following these considerations, we define people in this category as a success in the lower as well as in the upper bound scenario. Finally, people in the second category are measured as a success in the upper bound and as a failure in the lower bound scenario. The true success probability of leaving unemployment for any destination will lie within these boundaries. Obviously, the time during the programme is rated as a failure for the participants.

Outcomes over Time At first we will take a look at the success probabilities of participating individuals over time. We estimated the effects for the participants from March 2000 until March 2002. Participation in JCS reduces the search intensity during the programme period; therefore one has to consider the monthly exit 
rates of participants for interpretation, which are given in table A.3. As can be seen, the exit-rate for men in West Germany lies around 5\% per month during the first eleven months of the programme (for women slightly lower). The exit-rate reaches its peak after one year in February 2001 with $34.65 \%$ (women: $39.41 \%$ ) which is the regular duration for JCS. By that time $91.6 \%$ (86.4\%) of all men (women) have left the programme. At the same time $93.5 \%$ (93.1\%) of all men (women) have left the programmes in East Germany, too. An interesting difference is that the peak of exits here is much more pronounced after twelve months (Men: $69.42 \%$, women: $72.51 \%)$. That means that we observe the outcome for the majority of individuals for at least one year after the programme ends, even though for some individuals the observed time horizon is up to 23 months. In that sense we can only make statements regarding the short-term effects of the programmes. Given these exit rates, a locking-in effect during the first months after programme start has to be expected.

Figures B.1, B.2, B.3 and B.4 show the success probabilities, i.e. the differences in the outcomes between participants and matched non-participants, for West and East Germany over time. The success probabilities are differentiated by gender and the five sectors. Since the number of female participants in West Germany in the sectors 'Agriculture' and 'Construction \& Industry' has been too small (43 and 41), these sectors have been excluded from the analysis. The figures show the lower and upper bounds of the true treatment effect. An effect below the zero line means that the participants have on average a lower success probability than the matched non-participants.

The expected locking-in effects are clearly visible during the first months after programme start. Especially in East Germany the success probabilities are strongly decreasing in the first months, reaching their lowest value in the autumn of 2000. After that the effects are upward sloping. In West Germany a similar pattern can be found, even though the decrease in the beginning is not so pronounced due to the different exit behaviour.

As noted above we have estimated a lower and an upper bound for the effects. In most cases the lower bound of the effects lies in the first months above the upper bound which might be somewhat confusing. However, this is easily understandable if one looks at the construction of these bounds. The analysed participation (first treatment) is taken as a failure in both scenarios. Due to the fact that individuals from the control group may enter the category 2 status (registered job-seekers but not unemployed) and are then judged as a success in the upper bound scenario, the upper bound slips under the lower bound because nearly all participants are still in the programmes at that time. Since we cannot separate the locking-in effect from the treatment effect, we will start our interpretation when the majority of participants has left their programmes, that is after March 2001. 
Another consequence of the definition of the upper bound in connection with using the first treatment as a failure is an abrupt rise in the success probabilities after most programmes have ended. Almost all figures show this instance in February/March 2001. For some groups, e.g. men in 'Agriculture' or 'Construction \& Industry' in West Germany, this rise begins earlier due to shorter treatment durations.

While the mean upper bounds surge in March 2001 (after the majority of individuals have left the programmes), the lower bounds of the success probabilities are increasing only slowly. This results in a clear spread between the lower and the upper bounds of the success probabilities. The spread indicates a high proportion of participants, who could leave open unemployment after treatment, but are still registered job-seekers.

Since the purpose of JCS is to stabilise and qualify unemployed for the re-integration into regular employment, we expect an increasing success probability for participants after the programmes end. Due to the strong lockingin effect, the starting position for participants is on average lower than for the non-participants. However, since we observe the outcomes until two years after start of the programmes and one year after the majority of the individuals has left the programmes, a successful programme should overcompensate for this initial fall.

Sectoral Heterogeneity Table 6 summarises the effects for the treatment groups in the five sectors in March 2002 which is the end of our observation period. To give an example for the interpretation let us look at the effect for East German women in 'Agriculture'. The lower bound of the effect is $-13.59 \%$, the upper bound is $-6.38 \%$. That means that participants have a success probability which is between $6.38 \%$ and $13.59 \%$ lower as the success probability of non-participants. The differences between the sectors are enormous, e.g. the lower bounds of the effects for men in East Germany lie between $-12.29 \%$ ('Construction \& Industry') and $-25.32 \%$ ('Agriculture').

What is most striking is the fact that the success probabilities are significant negative for nearly all of the groups and sectors. The only exception are women in East Germany who participate in 'Community Services'. The upper bound effect for this group is $3.86 \%$. However, the lower bound for this group amounts to $-11.53 \%$. Since the true treatment effect lies somewhere between these boundaries, we cannot identify a persuasive positive effect.

Clearly programmes in some sectors are better than others, but overall none of the programmes helps its participants to have a higher success probability than non-participants two years after start. The sectors which are most harmful for participating individuals in West Germany are 'Construction \& Industry' for men (-19.39\% / -11.99\%) and 'Office \& Services' for women (-18.10\% / not significant). In East Germany 'Agriculture' is the 
Table 6: Average effects (in \%) for participants 24 months (Mar/02) after programme start - Sensitivity Analysis with Rosenbaum Bounds

\begin{tabular}{lcccccc}
\hline \hline & \multicolumn{3}{c}{ Upper Bound Scenario } & \multicolumn{3}{c}{ Lower Bound Scenario } \\
& ATET & $Q_{M H}$ & Critical & ATET & $Q_{M H}$ & Critical \\
Group & Mar/02 & for $e^{\gamma}=1$ & value of $e^{\gamma}$ & Mar $/ 02$ & for $e^{\gamma}=1$ & value of $e^{\gamma}$ \\
\hline West-Germany & & & & & & \\
Men & & & & & & \\
Agriculture & -1.68 & 0.45 & - & $\mathbf{- 1 1 . 9 4}$ & 16.87 & $1.01-1.05$ \\
Constr.\& Industry & $\mathbf{- 1 1 . 9 9}$ & 12.29 & $1.25-1.30$ & $\mathbf{- 1 9 . 3 9}$ & 31.28 & $1.01-1.05$ \\
Office \& Services & -3.73 & 0.14 & - & -16.42 & 6.09 & $1.01-1.05$ \\
Comm. Services & -6.34 & 2.47 & - & $\mathbf{- 1 5 . 8 5}$ & 16.34 & $1.10-1.15$ \\
Other & $\mathbf{- 9 . 4 3}$ & 16.23 & $1.20-1.25$ & $\mathbf{- 1 7 . 7 8}$ & 54.07 & $1.10-1.15$ \\
Women ${ }^{(a)}$ & & & & & & \\
Office \& Services & -4.29 & 1.08 & - & $\mathbf{- 1 8 . 1 0}$ & 15.61 & $1.01-1.05$ \\
Comm. Services & -4.13 & 2.02 & - & $\mathbf{- 1 5 . 9 5}$ & 27.70 & $1.01-1.05$ \\
Other & -4.44 & 1.28 & - & $\mathbf{- 1 4 . 3 3}$ & 12.88 & $1.10-1.15$ \\
\hline East-Germany & & & & & & \\
Men & & & & & & \\
Agriculture & $\mathbf{- 1 2 . 5 4}$ & 27.88 & $1.35-1.40$ & $\mathbf{- 2 5 . 3 2}$ & 119.99 & $1.10-1.15$ \\
Constr.\& Industry & -2.95 & 0.40 & - & $\mathbf{- 1 2 . 2 9}$ & 12.25 & $1.35-1.40$ \\
Office \& Services & -2.49 & 0.25 & - & $\mathbf{- 1 7 . 9 1}$ & 13.94 & $1.30-1.35$ \\
Comm. Services & -3.39 & 0.59 & - & $\mathbf{- 2 1 . 7 9}$ & 36.67 & $1.01-1.05$ \\
Other & $\mathbf{- 1 2 . 9 6}$ & 32.85 & $1.50-1.55$ & $\mathbf{- 2 3 . 2 6}$ & 119.37 & $1.20-1.25$ \\
Women & & & & & & \\
Agriculture & $\mathbf{- 6 . 3 0}$ & 7.60 & $1.01-1.05$ & $\mathbf{- 1 3 . 5 9}$ & 40.91 & $1.25-1.30$ \\
Constr.\& Industry & -2.13 & 0.27 & - & $\mathbf{- 1 5 . 9 6}$ & 12.69 & $1.05-1.10$ \\
Office \& Services & 2.16 & 0.79 & - & $\mathbf{- 1 4 . 5 1}$ & 29.84 & $1.30-1.35$ \\
Comm. Services & 3.86 & 4.95 & $1.75-1.80$ & $\mathbf{- 1 1 . 5 3}$ & 55.82 & $1.35-1.40$ \\
Other & -1.29 & 0.55 & - & $\mathbf{- 1 4 . 7 6}$ & 73.12 & $1.30-1.35$ \\
\hline \hline Bold & & & & & & \\
\hline
\end{tabular}

Bold letters indicate significance at the $1 \%$ level, Italic letters refer to the $5 \%$ level.

ATET Mar/02: Average effect (in \%) for participants 24 months after programme start.

$Q_{M H}$ : Value of the Mantel-Haensel test-statistic for ATE Mar/02.

- indicates that the effect has not been significant on the $5 \%$-level

(a) Effects for groups with less than 50 observations are omitted.

worst sector for men $(-25.32 \% /-12.84 \%)$ and 'Construction \& Industry' is the worst for women $(-15.96 \% /$ not significant). As all effects (apart from the upper bound of women in East Germany in 'Community Services') lie below that of the matched non-participants, JCS seem to have no positive impact on the success probabilities for participants up to 24 months after treatment.

Sensitivity Analysis with Rosenbaum Bounds Our estimation is based on the CIA which basically states that the distribution of covariates $\mathrm{X}$ is balanced between the treatment and the control group. If however, both groups differ on unobserved variables which affect simultaneously the assignment to treatment and the outcome variable a 'hidden bias' might arise. ${ }^{20}$ It should be clear, that matching estimators are not robust against this 'hidden bias'. Since it is not possible to estimate the magnitude of selection bias with non-experimental data,

\footnotetext{
${ }^{20}$ This bias is also said to arise on unobservable factors or unobserved heterogeneity.
} 
we address this problem with the bounding approach proposed by Rosenbaum (2002). The basic question to be answered is if inference about programme effects may be altered by unobserved factors. In other words, we want to determine how strongly an unmeasured variable must influence the selection process in order to undermine the implications of matching analysis. Two recent applications of this approach can be found in Aakvik (2001) and DiPrete and Gangl (2004). We will outline the basic idea of this approach in the following, an extensive discussion can be found in Rosenbaum (2002).

To do so let us rewrite the participation probability for individual $i$ with observed characteristics $x_{i}$ in a programme as

$$
\pi_{i}=\operatorname{Pr}\left(D_{i}=1 \mid x_{i}\right)=F\left(\beta x_{i}+\gamma u_{i}\right),
$$

where $u_{i}$ is the unobserved variable and $\gamma$ is the effect of $u_{i}$ on the participation decision. Clearly, if the study is free of hidden bias, $\gamma$ will be zero and the participation probability will solely be determined by $x_{i}$. However, if there is hidden bias, two individuals with the same observed covariates $x$ have differing chances of receiving treatment. Let us assume we have a matched pair of individuals $i$ and $j$ and further assume that $F$ is the logistics distribution. The odds that the individuals receive treatment are then given by $\frac{\pi_{i}}{\left(1-\pi_{i}\right)}$ and $\frac{\pi_{j}}{\left(1-\pi_{j}\right)}$, and the odds ratio is given by:

$$
\frac{\frac{\pi_{i}}{1-\pi_{i}}}{\frac{\pi_{j}}{1-\pi_{j}}}=\frac{\pi_{i}\left(1-\pi_{j}\right)}{\pi_{j}\left(1-\pi_{i}\right)}=\frac{\exp \left(\beta x_{j}+\gamma u_{j}\right)}{\exp \left(\beta x_{i}+\gamma u_{i}\right)}=\exp \left[\gamma\left(u_{i}-u_{j}\right)\right]
$$

If both units have the same observed covariates - as implied by the matching procedure - the $x$-vector cancels. But still, the individuals differ in their odds of receiving treatment by a factor that involves the parameter $\gamma$ and the difference in their unobserved covariates $u$. It is now the task of sensitivity analysis to evaluate how inference about the programme effect is altered by changing the values of $\gamma$ and $\left(u_{i}-u_{j}\right)$. We follow Aakvik (2001) and assume for the sake of simplicity that the unobserved covariate is a dummy variable with $u_{i} \in\{0,1\}$. A good example is the case where motivation plays a role for the participation decision and the outcome variable, and a person is either motivated $(u=1)$ or not $(u=0)$. Rosenbaum (2002) shows that (10) implies the following bounds on the ratio of the odds that either of the two matched individuals will receive treatment:

$$
\frac{1}{e^{\gamma}} \leq \frac{\pi_{i}\left(1-\pi_{j}\right)}{\pi_{j}\left(1-\pi_{i}\right)} \leq e^{\gamma}
$$

The two matched individuals have the same probability of participating only if $e^{\gamma}=1$. If $e^{\gamma}=2$, then individuals who appear to be similar (in terms of $x$ ), could differ in their odds of receiving the treatment by as much as factor of 2. In this sense, $e^{\gamma}$ is a measure of the degree of departure from a study that is free of hidden 
bias (Rosenbaum, 2002). Aakvik (2001) suggests to use the Mantel and Haenszel (1959) test statistic. To do so, some additional notation is needed. We observe the outcome $y$ some time after treatment for both participants and non-participants. If $y$ is unaffected by different treatment assignments $d$, the treatment is said to have no effect. If $y$ is different for different assignments, then the treatment has some positive (or negative) effect. To be significant, the treatment effect has to cross some test statistic. The Mantel-Haenszel nonparametric test compares the successful number of persons in the treatment group against the same expected number given the training effect is zero. Aakvik (2001) notes that the MH-test can be used to test for no treatment effect both within different strata of the sample and as a weighted average between strata. Under the nullhypothesis the distribution of $y$ is hypergeometric. We notate $n_{1 s}$ and $n_{0 s}$ as the numbers of treated and non-treated individuals in stratum $s$, where $n_{s}=n_{0 s}+n_{1 s} . y_{1 s}$ is the number of successful participants, $y_{0 s}$ is the number of successful non-participants, and $y_{s}$ is the number of total successes in stratum $s$. The teststatistic $Q_{M H}=\left(y_{1 s}-E\left(y_{1 s}\right) / \operatorname{Var}\left(s_{1 y}\right)\right)$ follows the chi-square distribution with one degree of freedom and is given by:

$$
Q_{M H}=\frac{U^{2}}{\operatorname{Var}(U)}=\frac{\left[\sum_{s=1}^{S}\left(y_{1 s}-\frac{n_{1 s} y_{s}}{n_{s}}\right)\right]^{2}}{\sum_{s=1}^{S} \frac{n_{1 s} n_{0 s} y_{s}\left(n_{s}-y_{s}\right)}{n_{s}^{2}\left(n_{s}-1\right)}} .
$$

To use a test-statistic like $t(d, y)$ we first have to make the treatment and the control group as equal as possible since the test is based on random sampling. Since this is done by our matching procedure, we can proceed to discuss the possible influences of $e^{\gamma}>1$. For fixed $e^{\gamma}>1$ and $u \in\{0,1\}$ Rosenbaum (2002) shows that the test-statistics $Q_{M H}$ can be bounded by two known distributions. As noted already, if $e^{\gamma}=1$ the bounds are equal to the 'base' scenario of no hidden bias. With increasing $e^{\gamma}$ the bounds move apart reflecting uncertainty about the test-statistics in the presence of unobserved selection bias. Two scenarios can be thought of. Let $Q_{M H}^{+}$be the test-statistics given that we have overestimated the treatment effect and $Q_{M H}^{-}$the case where we have underestimated the treatment effect.

The two bounds are then given by:

$$
Q_{M H}^{+}=\frac{\left[\sum_{s=1}^{S}\left(y_{1 s}-\widetilde{E}_{s}^{+}\right)\right]^{2}}{\sum_{s=1}^{S} \operatorname{Var}\left(\widetilde{E}_{s}^{+}\right)} \text {and } \quad Q_{M H}^{-}=\frac{\left[\sum_{s=1}^{S}\left(y_{1 s}-\widetilde{E}_{s}^{-}\right)\right]^{2}}{\sum_{s=1}^{S} \operatorname{Var}\left(\widetilde{E}_{s}^{-}\right)}
$$

where $\widetilde{E_{s}}$ and $\operatorname{Var}\left(\widetilde{E_{s}}\right)$ are the large sample approximations to the expectation and variance of the number of successful participants when $u$ is binary and for given $\gamma \cdot{ }^{21}$

\footnotetext{
${ }^{21}$ The large sample approximation of $\widetilde{E_{s}^{+}}$is the unique root of the following quadratic equation: $\widetilde{E}_{s}^{2}\left(e^{\gamma}-1\right)-\widetilde{E}_{s}\left[\left(e^{\gamma}-1\right)+\right.$ $\left.\left(n_{1 s}+y_{s}\right)+n_{s}\right]+e^{\gamma} y_{s} n_{1 s}$, with the addition of $\max \left(0, y_{s}+n_{1 s}-n_{s} \leq \widetilde{E_{s}} \leq \min \left(y_{s}, n_{1 s}\right)\right.$ to decide which root to use. $\widetilde{E}_{s}^{-}$is determined by replacing $e^{\gamma}$ by $\frac{1}{e^{\gamma}}$. The large sample approximation of the variance is given by
} 
Results of the Sensitivity Analysis The Rosenbaum bounds allow us now to test the sensitivity of our results in table 6 for varying degrees of unobserved differences in both scenarios of the underlying outcome variable. First of all, the table shows the results of the Mantel and Haenszel (1959) test-statistic for the situation free of hidden bias. As shown above, $e^{\gamma}$ is a measure of the degree of departure from a study that is free from 'hidden bias'. The test statistic $Q_{M H}$ for $e^{\gamma}=1$ reflects the situation with no 'hidden bias'. A $\chi^{2}$-value below 3.84 indicates that the treatment effect is not significant. Clearly, a sensitivity analysis for insignificant effects is not meaningful and hence will be omitted. For the effects which are significant in the first place we gradually increase the level of $e^{\gamma}$ until the inference about the treatment effect is changed. In other words, we are assessing the strength unmeasured influences would require in order that the inference about the treatment effect is changed.

The interpretation is straightforward: If we look at the effect for men in the 'Construction \& Industry' sector in West-Germany we see that the effect in the upper bound scenario is $-11.94 \%$ and significant. The critical value of $e^{\gamma}$ is between $1.25-1.30$. A critical value of 1.30 would suggest that individuals that have the same $x$-vector differ in their odds of participating in treatment by a factor of 1.30 , or $30 \%$. It is important to note that these are worst-case scenarios. A critical value of $e^{\gamma}=1.30$ does not mean that there is unobserved heterogeneity present and that there is no effect of treatment on the outcome variable. This result only means that the confidence interval for the effect would include zero if an unobserved variable caused the odds ratio of treatment assignment to differ between treatment and control groups by 1.30 and if this variable's effect on the outcome is so strong that it almost perfectly determines the outcome in each pair of matched cases in the data. Hence, even if there is unobserved heterogeneity to a degree of $e^{\gamma}=1.25$ in the group of West-German men in 'Construction \& Industry', inference about the treatment effect would not be changed. The results in this table make clear that for most groups a relatively high level of 'hidden bias' could be in the data without changing the inference about the treatment effects. However, some exceptions can be found and some restrictions apply. For some of the sub-populations, especially for men and women in West-Germany under the lower bound scenario, the critical value of $e^{\gamma}$ is somewhere below 1.05. That implies that even small magnitudes of 'hidden bias' would alter the inference and consequently interpretation for these sub-populations hinges on this restriction.

Outcomes for the Sub-Populations What is left to examine is the individual heterogeneity. Even though the programmes do not work for the participants as a whole, it might be the case that they work for some $\operatorname{Var}\left(\widetilde{E}_{s}\right)=\left(\frac{1}{\widetilde{E}_{s}}+\frac{1}{y_{s}-\widetilde{E}_{s}}+\frac{1}{n_{1 s}-\widetilde{E}_{s}}+\frac{1}{n_{s}-y_{s}-n_{1 s}-\widetilde{E}_{s}}\right)^{-1}$. 
Table 7: Average effects (in \%) for participants 24 months (Mar/02) after programme start

\begin{tabular}{ccccc}
\hline \hline Agriculture & $\begin{array}{c}\text { Construction \& } \\
\text { Industry }\end{array}$ & Office \& Services & $\begin{array}{c}\text { Community } \\
\text { Services }\end{array}$ & Other \\
\hline $\begin{array}{l}\text { Lower- Upper- No. Lower- Upper- No. } \\
\text { bound bound } \\
\text { bound bound }\end{array}$ & $\begin{array}{l}\text { Lower- Upper- No. } \\
\text { bound bower- Upper- No. } \\
\text { bound } \\
\text { bound bound }\end{array}$ & $\begin{array}{l}\text { Lower- Upper- No. } \\
\text { bound } \\
\text { bound }\end{array}$ \\
\hline
\end{tabular}

Men in West Germany

\begin{tabular}{|c|c|c|c|c|c|c|c|c|c|c|c|c|c|c|c|}
\hline \multicolumn{16}{|c|}{ Age (in years) } \\
\hline$<26$ & -11.34 & -5.15 & 98 & -6.98 & -3.10 & 130 & - & - & - & -19.30 & -15.79 & 114 & -15.65 & -10.87 & 230 \\
\hline $26-50$ & -10.37 & 0.29 & 349 & -10.50 & -6.39 & 219 & -9.90 & 0.00 & 103 & -10.15 & 0.00 & 198 & -16.45 & -7.79 & 463 \\
\hline$>50$ & -8.70 & 3.26 & 93 & - & - & - & - & - & - & - & - & - & -23.29 & -6.16 & 146 \\
\hline \multicolumn{16}{|c|}{ Unemployment duration (in weeks) } \\
\hline$<13$ & -16.80 & -5.60 & 126 & -6.35 & -1.59 & 126 & - & - & - & -24.11 & -16.07 & 112 & -16.13 & -6.45 & 248 \\
\hline $3-52$ & -17.88 & -7.82 & 179 & -15.67 & -10.45 & 135 & - & - & - & -6.72 & 0.75 & 134 & -18.25 & -11.93 & 285 \\
\hline$>52$ & -12.50 & -3.02 & 235 & -4.55 & 1.52 & 132 & -5.88 & 11.76 & 69 & -9.90 & 4.95 & 103 & -16.72 & -7.87 & 306 \\
\hline
\end{tabular}

Women in West Germany

Age (in years)

\begin{tabular}{|c|c|c|c|c|c|c|c|c|c|c|c|c|c|c|c|}
\hline$<26$ & - & - & - & - & - & - & - & - & - & -21.05 & -14.04 & 114 & -12.20 & -7.32 & 82 \\
\hline $26-50$ & - & - & - & - & - & - & -17.88 & -1.32 & 152 & -17.30 & -3.81 & 342 & -12.57 & 0.00 & 175 \\
\hline$>50$ & - & - & - & - & - & - & - & - & - & -3.85 & 7.69 & 79 & - & - & - \\
\hline \multicolumn{16}{|c|}{ Unemployment duration (in weeks) } \\
\hline$<13$ & - & - & - & - & - & - & -22.45 & -8.16 & 50 & -18.75 & -8.59 & 129 & -18.29 & -6.10 & 82 \\
\hline $13-52$ & - & - & - & - & - & - & -33.33 & -14.29 & 84 & -19.23 & -7.21 & 208 & -29.13 & -16.50 & 103 \\
\hline$>52$ & - & - & - & - & - & - & 5.19 & 11.69 & 78 & -14.21 & -1.02 & 198 & 2.78 & 7.41 & 108 \\
\hline
\end{tabular}

Age (in years)

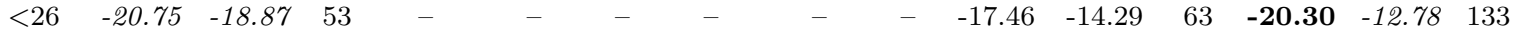

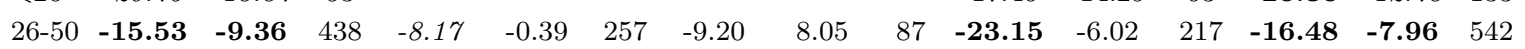

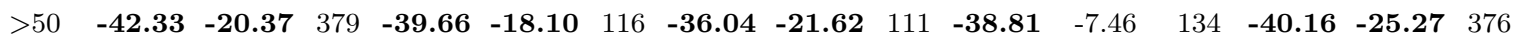

Unemployment duration (in weeks)

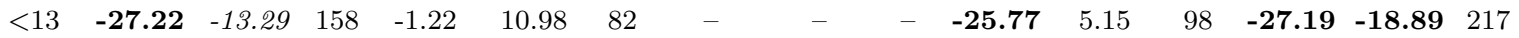

$\begin{array}{llllllllllllllll}13-52 & \mathbf{- 2 2 . 2 9} & -4.52 & 333 & -9.20 & 6.32 & 174 & \mathbf{- 2 6 . 3 2} & -8.42 & 95 & \mathbf{- 1 5 . 8 2} & 3.57 & 196 & \mathbf{- 2 0 . 5 3} & \mathbf{- 9 . 2 7} & 455\end{array}$

$\begin{array}{llllllllllllllll}>52 & \mathbf{- 2 2 . 9 6} & \mathbf{- 1 4 . 5 1} & 379 & \mathbf{- 2 5 . 8 3} & \mathbf{- 1 9 . 2 1} & 151 & -17.65 & -1.47 & 69 & -7.50 & 0.00 & 120 & \mathbf{- 2 2 . 6 9} & \mathbf{- 1 2 . 1 4} & 379\end{array}$

Age (in years)

\begin{tabular}{lccccccccccccccc}
$<26$ & - & - & - & - & - & - & - & - & - & -11.11 & -8.33 & 73 & -2.70 & 8.11 & 74 \\
$26-50$ & $\mathbf{- 1 5 . 0 1}$ & $\mathbf{- 1 1 . 3 7}$ & 633 & -10.32 & 5.56 & 126 & $\mathbf{- 8 . 4 5}$ & 5.56 & 416 & $\mathbf{- 7 . 8 7}$ & $\mathbf{7 . 7 8}$ & 1170 & $\mathbf{- 1 1 . 0 4}$ & 0.52 & 970 \\
$>50$ & $\mathbf{- 1 9 . 6 9}$ & -3.86 & 259 & $\mathbf{- 3 0 . 3 6}$ & -21.43 & 56 & $\mathbf{- 3 1 . 1 1}$ & -10.22 & 225 & $\mathbf{- 2 5 . 8 7}$ & $\mathbf{- 9 . 7 9}$ & 572 & $\mathbf{- 2 3 . 7 3}$ & -3.69 & 435 \\
Unemployment & duration (in weeks) & & & & & & & & & & & \\
$<13$ & -17.07 & -4.88 & 83 & - & - & - & $\mathbf{- 2 4 . 4 2}$ & -9.30 & 86 & $\mathbf{- 2 2 . 1 6}$ & 0.00 & 186 & $\mathbf{- 2 3 . 6 2}$ & -8.04 & 199 \\
$13-52$ & -1.67 & 5.00 & 300 & $\mathbf{- 2 7 . 1 4}$ & -7.14 & 70 & $\mathbf{- 2 1 . 5 3}$ & -1.09 & 276 & $\mathbf{- 1 3 . 2 4}$ & 4.72 & 764 & $\mathbf{- 1 3 . 2 0}$ & 2.29 & 569 \\
$>52$ & - & - & - & $\mathbf{- 2 1 . 5 9}$ & -6.82 & 88 & $\mathbf{- 1 0 . 4 2}$ & 3.13 & 288 & $\mathbf{- 9 . 9 4}$ & -0.46 & 865 & $\mathbf{- 1 1 . 1 3}$ & -0.56 & 711 \\
\hline \hline
\end{tabular}

Bold letters indicate significance at the $1 \%$ level, Italic letters refer to the $5 \%$ level.

- Effects for groups with less than 50 observations are omitted.

sub-populations. One could assume e.g. that they are especially effective for the explicit target groups of JCS.

Table 7 shows the effects on the success probabilities for the six sub-populations under consideration 24 months after programmes start. Besides the lower and upper bounds of the effects, the number of participants in the respective strata is given. Sub-groups with less than 50 observations were excluded from the analysis.

The only significant positive effect can be found for women between 26 and 50 years who participate in the sector 'Community \& Services' in East Germany; their effect lies between $-7.87 \%$ and $7.78 \%$. For the rest of 
the groups the effects are at best insignificant. However, for the majority of the groups a participation in JCS has strongly negative impacts two years after programme start. Surprisingly, even the target groups (young and long-term unemployed) have no significant positive effects. On the contrary, long-term unemployed (over 52 weeks) men in East Germany have success probabilities between $-25.83 \%$ (lower bound for 'Construction \& Industry') and $-12.14 \%$ (upper bound for 'Other'). For the long-term unemployed men and women in West Germany as well as for women in East Germany only few significant (all negative) results can be found. Due to the limited number of observations an assessment of the situation of young unemployed can only be given for a small number of groups. For women in East Germany no significant effects are found, young men in East Germany have effects between -20,75\% (lower bound for 'Agriculture') and - $-12.78 \%$ (upper bound for 'Other'). The effect for young men and women participating in 'Community Services' is similarly bad.

The worst success probabilities are estimated for older (over 50 years) men in East Germany throughout all sectors. For older women in East Germany the situation is slightly better, even though the significant results still lie between $-31.11 \%$ (lower bound for 'Office \& Services') and $-9.79 \%$ (upper bound for 'Community Services') and therefore below those of non-participants.

Considering different unemployment durations before treatment shows no different picture. The success probabilities of the participants are here below those of the non-participants, too. Again, the effects are at best insignificant. The worst effects can be found for men in West Germany who have been short-term unemployed and participate in 'Community Services' (-24.11\% / -16.07\%). Women in the same region with an unemployment duration between 13 and 52 weeks participating in 'Office \& Services' (-33.33\% / -14.29\%) are even worse off. In East Germany e.g. short-term unemployed men in the sector 'Others' (-27.19\% / -18.89\%) and women with 13-52 weeks of unemployment participating in 'Construction \& Industry' (-27.14\% / not significant) have the most negative results.

\subsection{Policy Conclusions}

As already mentioned, the main purpose of JCS is the stabilisation and qualification of unemployed individuals in order to re-integrate them into the first labour market. Particular target groups are young unemployed without professional training and long-term unemployed, even though the composition of the participants in our dataset does not show a clear concentration on these groups. Tables A.1 and A.2 show that the majority of participants in West Germany throughout all sectors is between 25 and 50 years old. The share of short-term 
unemployed is here higher than could be expected (between 21.26\% and 32.26\%). In East Germany, the share of people between 25 and 50 years is even larger, whereas the share of young unemployed only lies between $1.53 \%$ and $8.19 \%$. With respect to unemployment duration the majority of participants belongs to the target group.

To get a clear picture of the treatment effects we accounted for several sources of heterogeneity in our estimation. Besides regional and gender-specific differences we also allowed for sectoral and individual heterogeneity. We also tested the sensitivity of the results with respect to unobserved heterogeneity or 'hidden bias'. Especially for West-Germany we have found that the results in our lower bound scenario are sensitive to 'hidden bias' and hence this restriction applies for interpretation. However, given the fact that we have a strong dataset, i.e. a large number of explanatory variables, we have reason to believe that the problem of unobserved heterogeneity is less important, allowing us to draw some policy conclusions.

As expected the effects showed a wide span in different sub-populations and different sectors of JCS. However, the most striking finding is that no significant positive effects can be established for any sub-population in any sector. ${ }^{22}$ The initial negative effect of participation could not be overcompensated during our observation period until March 2002, even though most of the sub-populations show increasing success probabilities after the first months. Since we can observe the outcome for the individuals for two years after the programme starts and for the majority of people for at least one year after it ends, it is reasonable to assume that the locking-in effect is of minor importance in March 2002.

Thus, the question arises why participants have on average significantly lower success probabilities on the labour market than comparable non-participants. One reason might be the often cited 'stigma-effects'. If the programme is targeted at people with 'disadvantages', there is always a risk that a possible employer takes participation in such schemes as a negative signal concerning the expected productivity or motivation. If that is the case, the hoped-for positive effects of JCS might vanish. Another reason might be the already mentioned locking-in effect during the first months of treatment. Even though participants in JCS should continue searching for a new job, it is questionable whether this is realistic. Due to their occupation in the programme they will have a reduced search intensity. This is only justifiable if one thinks that being in the measure per se will pay off later on, e.g. through positive effects on the employability or increased human capital through qualification in the programme. It seems that neither of the two goals (employability and

\footnotetext{
${ }^{22}$ The only exception is the upper bound for women in 'Community Services' in East Germany.
} 
qualification) can be achieved in a satisfying way which would result in a positive success probability. Therefore it is debatable whether the design of the programmes is appropriate. One possibility would be to shorten the treatment durations. To become employable i.e. to give possible employers a positive signal it might be sufficient to participate in a programme for less than one year, which is the regular duration at the moment. Since JCS seem to miss the purpose of qualifying participants for re-integration in the labour market, another proposition is a higher share of qualifying elements during the programme. This might, together with regular inspections of the progress, enhance the human capital of the participating individuals and therefore lead to noticeable increased success probabilities. Another issue is the massive utilisation of JCS particularly in East Germany. Reflecting the composition of the participating individuals, a special focus on target groups is not visible. A clear concentration on the 'disadvantaged' and a specific placement of participants with respect to their qualification might be necessary. This would lead to a reduced number of participants and a clearer focus on specific target groups. Given that, the additional nature of these schemes might be unnecessarily restrictive. If JCS are not allowed to compete with regular employment, the benefit out of an occupation in these schemes might not be comparable to real labour market experience either. This might undermine one of its explicit goals that is the qualification and stabilisation and finally re-integration of the individual into the first labour market. However, if the 'disadvantages' of the target groups are too strong, an integration into the first labour market might be unlikely. In this case JCS might also be used as a 'social' policy, e.g. for stabilisation, crime prevention, etc. Obviously, a clear re-definition of goals and target groups is a necessary precondition for such a step.

\section{Summary and Outlook}

This paper presents a microeconometric evaluation of JCS in Germany. We focus on the effects on the participating individuals and take several sources of heterogeneity into account. Since previous empirical studies of these measures have been based on relatively small datasets, this is the first study which allows to draw policy-relevant conclusions. Our estimation is based on a very informative and exhaustive dataset merged from different administrative sources of the FEA. It contains information on all participants in JCS who started their programme in February 2000. The pool of variables can be differentiated into four categories: Socio-demographic, qualification and career information as well as regional context-variables to take account of the situation on the local labour market. The exhaustive and informative dataset at hand justifies the conditional independence assumption 
and therefore we applied a matching estimator. Besides avoiding functional form assumptions, this estimator is intuitively appealing and allows the effects to be different in specific sub-populations. Additionally, the multiple treatment framework is used to take into account sectoral heterogeneity within the analysed programme. We have also tested the sensitivity of our results with respect to 'hidden bias' and found that some of the results especially for the lower bound scenario in West-Germany - might not be robust against this form of bias. Even though we believe that - given our dataset - the problem of 'hidden bias' is not too severe, interpretation of the results hinges on this restriction.

The effects are estimated separately for men and women in West and East Germany participating in one of the five biggest sectors of JCS, considering regional, gender-specific and sectoral heterogeneity. To allow additionally for individual heterogeneity we also estimate the effects for various strata of the population, defined by age and the duration of previous unemployment. Our results show considerable differences with respect to these sources of heterogeneity. However, two things are very common throughout all groups. First, a strong locking-in effect during the first months of the programmes can be found. Second, although the success probabilities are increasing in the following, the most striking finding is that no significant positive effects can be established for any sub-population at the end of our observation period. Clearly, based on these findings the design and implementation of JCS has to be revised substantially. Some suggestions, like a shorter duration, a stricter concentration on specific target groups and more qualification elements are discussed in the paper.

Three main points should be examined in further studies. First, the observation period should be extended to check if there are any long-term effects of JCS which we could not detect yet. It can be argued that the observation period is too short for the final identification of the treatment effects, even though this seems to be unlikely in our view. Second, the used outcome variable does not allow to identify if individuals are re-integrated into regular employment. Even though this approach is comparable to our definition of the lower bound of the treatment effect, divergences have to be checked as soon as these data are available. Third, the interactions between active and passive elements of labour market policies should be analysed. It is a relevant question if JCS set the right incentives for the participating individuals, e.g. concerning monetary aspects. In this context it would also be interesting to evaluate the effects of the programme on the income of participants. 


\section{References}

AAKvik, A. (2001): "Bounding a matching estimator: the case of a Norwegian training program," Oxford Bulletin of Economics and Statistics, 63(1), 115-143.

Blundell, R., And M. Costa Dias (2000): "Evaluation Methods for Non-Experimental Data," Fiscal Studies, $21(4), 427-468$.

Brodaty, T., B. Crepon, and D. Fougere (2001): "Using Matching Estimators to Evaluate Alternative Youth Employment Programs: Evidence from France, 1986-1988," in Econometric Evaluation of Labour Market Policies, ed. by . echner, and F. Pfeiffer, pp. 85-123. Physica-Verlag.

Bundesanstalt für Arbeit (2001): Arbeitsmarkt 2000 - Amtliche Nachrichten der Bundesanstalt für Arbeit 49. Jahrgang, Nürnberg.

Bundesanstalt für Arbeit (2002): Arbeitsmarkt 2001 - Amtliche Nachrichten der Bundesanstalt für Arbeit 50. Jahrgang, Nürnberg.

DiPrete, T., and M. Gangl (2004): "Assessing Bias in the Estimation of Causal Effects: Rosenbaum Bounds on Matching Estimators and Instrumental Variables Estimation with Imperfect Instruments," Working Paper, WZB.

Gerfin, M., And M. Lechner (2002): "A Microeconometroc Evaluation of the Active Labour Market Policy in Switzerland," The Economic Journal, 112, 854-893.

Heckman, J., H. Ichimura, J. Smith, and P. Todd (1998): "Characterizing Selection Bias Using Experimental Data," Econometrica, 66, 1017-1098.

Heckman, J., H. Ichimura, and P. Todd (1998): "Matching as an Econometric Evaluation Estimator," Review of Economic Studies, 65, 261-294.

Holland, P. (1986): "Statistics and Causal Inference," Journal of the American Statistical Association, 81, 945-970.

Hujer, R., And M. Caliendo (2001): "Evaluation of Active Labour Market Policy - Methodological Concepts and Empirical Estimates," in Soziale Sicherung in einer dynamischen Gesellschaft, ed. by I. Becker, N. Ott, and G. Rolf, pp. 583-617. Campus-Verlag. 
Imbens, G. (2000): "The Role of the Propensity Score in Estimating Dose-Response Functions," Biometrika, $87(3), 706-710$.

Lechner, M. (2001): "Identification and estimation of causal effects of multiple treatments under the conditional independence assumption," in Econometric Evaluation of Labour Market Policies, ed. by M. Lechner, and F. Pfeiffer, pp. 1-18. Physica-Verlag, Heidelberg.

(2002a): "Programme Heterogeneity and Propensity Score Matching: An Application to the Evaluation of Active Labor Market Policies," The Review of Economics and Statistics, 84(2), 205-220.

(2002b): "Some practical issues in the evaluation of heterogenous labour market programmes by matching methods," Journal of the Royal Statistical Society, A, 165, 59-82.

Lechner, M., and R. Miquel (2001): "A Potential Outcome Approach to Dynamic Programme Evaluation - Part I: Identification," Discussion Paper, SIAW.

Mantel, N., And W. Haenszel (1959): "Statistical Aspects of the Analysis of Data from Retrospective Studies of Disease," Journal of the National Cancer Institute, 22, 719-748.

Rosenbaum, P., and D. Rubin (1983): "The Central Role of the Propensity Score in Observational Studies for Causal Effects," Biometrica, 70, 41-50.

(1985): "Constructing a Control Group Using Multivariate Matched Sampling Methods that Incorporate the Propensity Score," The American Statistican, 39, 33-38.

Rosenbaum, P. R. (2002): Observational Studies. Springer, New York.

Roy, A. (1951): "Some Thoughts on the Distribution of Earnings," Oxford Economic Papers, 3, 135-145.

Rubin, D. (1974): "Estimating Causal Effects to Treatments in Randomised and Nonrandomised Studies," Journal of Educational Psychology, 66, 688-701.

(1977): "Assignment to Treatment Group on the Basis of a Covariate," Journal of Educational Studies, $2,1-26$.

(1980): "Comment on Basu, D. - Randomization Analysis of Experimental Data: The Fisher Randomization Test," Journal of the American Statistical Association, 75, 591-593. 
Sianesi, B. (2004): "An Evaluation of the Active Labour Market Programmes in Sweden," The Review of Economics and Statistics, 86(1), 133-155.

Smith, J., and P. Todd (2004): "Does Matching Overcome LaLonde's Critique of Nonexperimental Estiamtors?," Journal of Econometrics, forthcoming.

VAn Ours, J. (2002): "The locking-in effect of subsidized jobs," Discussion Paper No. 2002-60, CentER. 


\section{A Tables}

Table A.1: Selected Descriptives - January 2000 - West-Germany

\begin{tabular}{|c|c|c|c|c|c|c|}
\hline & $\begin{array}{c}\text { Non- } \\
\text { Participants }\end{array}$ & Agriculture & $\begin{array}{l}\text { Construction } \\
\text { \& Industry }\end{array}$ & $\begin{array}{l}\text { Office \& } \\
\text { Services }\end{array}$ & $\begin{array}{c}\text { Community } \\
\text { Services }\end{array}$ & Other $^{3}$ \\
\hline Number & 85,195 & 583 & 434 & 348 & 884 & 1,132 \\
\hline \multicolumn{7}{|c|}{ Means } \\
\hline Programme duration (days) $^{1}$ & - & 262.41 & 276.28 & 319.11 & 294.49 & 281.97 \\
\hline Duration of unempl. (weeks) & 72.31 & 66.79 & 53.66 & 63.65 & 53.13 & 58.98 \\
\hline Duration of last empl. (months) & 64.96 & 14.82 & 17.47 & 29.67 & 21.26 & 20.34 \\
\hline Age & 42.81 & 37.76 & 33.89 & 40.58 & 35.85 & 36.43 \\
\hline Number of placement propositions & 3.15 & 8.14 & 6.38 & 8.28 & 6.25 & 7.11 \\
\hline German & 0.83 & 0.85 & 0.86 & 0.94 & 0.89 & 0.83 \\
\hline Last contact to job center & 2.46 & 2.29 & 2.38 & 2.72 & 2.57 & 2.41 \\
\hline Rehabilitation attendant & 0.05 & 0.05 & 0.05 & 0.08 & 0.04 & 0.04 \\
\hline Placement restraints & 0.19 & 0.17 & 0.13 & 0.18 & 0.14 & 0.15 \\
\hline Women & 0.45 & 0.07 & 0.09 & 0.61 & 0.61 & 0.26 \\
\hline Work experience & 0.91 & 0.90 & 0.86 & 0.83 & 0.83 & 0.84 \\
\hline Number of children & 0.49 & 0.50 & 0.40 & 0.53 & 0.52 & 0.41 \\
\hline Married & 0.56 & 0.36 & 0.34 & 0.44 & 0.35 & 0.34 \\
\hline \multicolumn{7}{|c|}{ Frequencies in $\%$} \\
\hline \multicolumn{7}{|l|}{ Occupational group } \\
\hline cultivation, breeding, fishery & 2.92 & 16.30 & 8.06 & 1.44 & 2.04 & 5.74 \\
\hline mining, mineral extraction & 0.39 & 0.34 & 0.46 & 0.09 & & \\
\hline manufacturing & 36.35 & 51.63 & 62.21 & 8.05 & 23.42 & 47.35 \\
\hline technical professions & 3.95 & 0.86 & 0.92 & 9.77 & 1.36 & 2.74 \\
\hline service professions & 54.33 & 28.82 & 24.88 & 78.45 & 70.59 & 40.11 \\
\hline other professions & 2.06 & 2.06 & 3.46 & 2.30 & 2.60 & 3.98 \\
\hline \multicolumn{7}{|l|}{ Professional training $(\mathrm{PT})$} \\
\hline without compl. PT, without CSE & 14.00 & 33.28 & 31.34 & 3.74 & 12.44 & 22.53 \\
\hline without compl. PT, with CSE & 36.70 & 37.22 & 44.01 & 23.56 & 37.33 & 38.87 \\
\hline industrial training & 41.30 & 27.10 & 22.58 & 44.25 & 28.17 & 28.62 \\
\hline Full-time vocational school & 1.60 & 0.17 & 0.69 & 2.87 & 2.26 & 0.88 \\
\hline Technical school & 2.54 & 1.03 & 0.46 & 6.32 & 6.11 & 1.94 \\
\hline Polytechnic & 1.17 & 0.34 & 0.23 & 5.75 & 6.11 & 2.30 \\
\hline College/ University & 2.68 & 0.86 & 0.69 & 13.51 & 7.58 & 4.86 \\
\hline \multicolumn{7}{|l|}{ Professional rank } \\
\hline worker, not skilled worker & 19.88 & 42.37 & 35.25 & 7.47 & 15.95 & 25.09 \\
\hline worker, skilled worker & 10.36 & 5.32 & 6.68 & 4.02 & 4.41 & 7.24 \\
\hline $\mathrm{WC}^{2}$, simple occupations & 11.48 & 2.06 & 2.76 & 21.26 & 15.16 & 6.63 \\
\hline $\mathrm{WC}^{2}$, advanced occupations & 4.39 & 1.37 & 0.92 & 12.07 & 9.28 & 4.06 \\
\hline other & 53.90 & 48.89 & 54.38 & 55.17 & 55.20 & 56.98 \\
\hline \multicolumn{7}{|c|}{ Underemployment rate of job center (4. quarter 1999) } \\
\hline$<10 \%$ & 28.56 & 23.84 & 18.66 & 35.34 & 32.92 & 30.04 \\
\hline $10 \%-12,5 \%$ & 25.03 & 28.99 & 15.21 & 22.13 & 30.66 & 23.94 \\
\hline $12,5 \%-15 \%$ & 34.99 & 32.76 & 52.76 & 29.89 & 25.68 & 36.93 \\
\hline$>15 \%$ & 11.42 & 14.41 & 13.36 & 12.64 & 10.75 & 9.10 \\
\hline \multicolumn{7}{|l|}{ Age classes (in years) } \\
\hline$<25$ & 11.14 & 19.21 & 33.87 & 7.76 & 25.79 & 27.56 \\
\hline $25-50$ & 53.54 & 64.49 & 54.38 & 73.28 & 61.09 & 56.36 \\
\hline$>50$ & 35.32 & 16.30 & 11.75 & 18.97 & 13.12 & 16.08 \\
\hline \multicolumn{7}{|c|}{ Duration of unemployment in classes (in weeks) } \\
\hline$<13$ & 26.36 & 24.19 & 32.26 & 21.26 & 27.26 & 29.15 \\
\hline $13-52$ & 33.81 & 32.25 & 35.02 & 36.49 & 38.69 & 34.28 \\
\hline$>52$ & 39.83 & 43.57 & 32.72 & 42.24 & 34.05 & 36.57 \\
\hline
\end{tabular}

\footnotetext{
1 The programme duration is measured after the individual has left the programme.

${ }^{2} \mathrm{WC}=$ white-collar worker

3 The sector 'Other' consists of 'Forestry', 'Traffic Systems', 'Supplemental Construction' and 'Other'.
} 
Table A.2: Selected Descriptives - January 2000 - East-Germany

\begin{tabular}{|c|c|c|c|c|c|c|}
\hline & $\begin{array}{c}\text { Non- } \\
\text { Participants }\end{array}$ & Agriculture & $\begin{array}{l}\text { Construction } \\
\text { \& Industry }\end{array}$ & $\begin{array}{c}\text { Office } \\
\text { \&Services }\end{array}$ & $\begin{array}{c}\text { Community } \\
\text { Services }\end{array}$ & Other $^{3}$ \\
\hline Number & 147,204 & 1,791 & 595 & 851 & 2,229 & 2,529 \\
\hline \multicolumn{7}{|c|}{ Means } \\
\hline Programme duration (days) $^{1}$ & - & 326.29 & 279.10 & 336.38 & 334.21 & 331.71 \\
\hline Duration of unempl. (weeks) & 65.93 & 64.11 & 53.10 & 58.50 & 60.42 & 58.12 \\
\hline Duration of last empl. (months) & 58.75 & 25.85 & 20.60 & 35.13 & 30.65 & 27.93 \\
\hline Age & 42.71 & 44.52 & 42.91 & 46.10 & 43.92 & 43.33 \\
\hline Number of placement propositions & 2.80 & 4.98 & 6.48 & 6.33 & 5.69 & 5.62 \\
\hline German & 0.98 & 1.00 & 0.99 & 1.00 & 1.00 & 0.99 \\
\hline Last contact to job center & 2.77 & 2.59 & 2.42 & 2.58 & 2.60 & 2.60 \\
\hline Rehabilitation attendant & 0.06 & 0.03 & 0.05 & 0.04 & 0.06 & 0.05 \\
\hline Placement restraints & 0.14 & 0.08 & 0.08 & 0.08 & 0.12 & 0.10 \\
\hline Women & 0.54 & 0.51 & 0.32 & 0.76 & 0.81 & 0.59 \\
\hline Work experience & 0.89 & 0.92 & 0.92 & 0.92 & 0.89 & 0.89 \\
\hline Number of children & 0.53 & 0.67 & 0.60 & 0.65 & 0.68 & 0.61 \\
\hline Married & 0.57 & 0.61 & 0.56 & 0.75 & 0.67 & 0.57 \\
\hline \multicolumn{7}{|c|}{ Frequencies in \% } \\
\hline \multicolumn{7}{|l|}{ Occupational group } \\
\hline cultivation, breeding, fishery & 5.25 & 15.69 & 9.24 & 2.59 & 2.65 & 5.85 \\
\hline mining, mineral extraction & 0.15 & 0.17 & 0.04 & & & \\
\hline manufacturing & 34.57 & 43.38 & 58.32 & 5.64 & 19.34 & 34.95 \\
\hline technical professions & 4.44 & 2.90 & 2.52 & 16.10 & 4.49 & 6.45 \\
\hline service professions & 53.16 & 37.30 & 29.58 & 75.68 & 72.99 & 51.96 \\
\hline other professions & 2.42 & 0.56 & 0.34 & 0.54 & 0.75 & \\
\hline \multicolumn{7}{|l|}{ Professional training $(\mathrm{PT})$} \\
\hline without compl. PT, without CSE & 5.60 & 10.78 & 9.41 & 0.59 & 1.93 & 5.42 \\
\hline without compl. PT, with CSE & 19.96 & 21.22 & 18.49 & 11.87 & 17.90 & 22.10 \\
\hline industrial training & 66.05 & 63.87 & 69.92 & 57.34 & 62.27 & 58.96 \\
\hline Full-time vocational school & 0.88 & 0.78 & 0.34 & 1.88 & 2.47 & 1.30 \\
\hline Technical school & 4.32 & 1.95 & 1.34 & 16.69 & 10.86 & 7.83 \\
\hline Polytechnic & 0.77 & 0.45 & 0.34 & 3.41 & 1.17 & 0.95 \\
\hline College/ University & 2.41 & 0.95 & 0.17 & 8.23 & 3.41 & 3.44 \\
\hline \multicolumn{7}{|l|}{ Professional rank } \\
\hline worker, not skilled worker & 20.40 & 38.19 & 36.47 & 12.93 & 21.44 & 26.18 \\
\hline worker, skilled worker & 21.44 & 15.35 & 20.00 & 15.63 & 16.60 & 15.94 \\
\hline $\mathrm{WC}^{2}$, simple occupations & 6.69 & 2.07 & 2.69 & 15.86 & 11.53 & 9.17 \\
\hline $\mathrm{WC}^{2}$, advanced occupations & 1.89 & 0.78 & 0.50 & 3.88 & 2.47 & 1.42 \\
\hline other & 49.58 & 43.61 & 40.34 & 51.70 & 47.96 & 47.29 \\
\hline \multicolumn{7}{|c|}{ Underemployment rate of job center (4. quarter 1999) } \\
\hline$<20 \%$ & 2.45 & 0.61 & 2.86 & 0.82 & 2.42 & 3.44 \\
\hline $20 \%-22,5 \%$ & 6.44 & 6.20 & 12.27 & 10.58 & 6.42 & 4.63 \\
\hline $22,5 \%-25 \%$ & 37.88 & 27.19 & 23.19 & 32.78 & 36.61 & 46.30 \\
\hline $25 \%-27,5 \%$ & 18.31 & 18.09 & 25.88 & 19.27 & 22.52 & 12.89 \\
\hline $27,5 \%-30 \%$ & 23.18 & 25.68 & 25.55 & 26.79 & 19.61 & 23.13 \\
\hline$>30 \%$ & 11.75 & 22.22 & 10.25 & 9.75 & 12.43 & 9.61 \\
\hline \multicolumn{7}{|l|}{ Age classes (in years) } \\
\hline$<25$ & 11.77 & 4.58 & 6.72 & 1.53 & 6.10 & 8.19 \\
\hline $25-50$ & 55.04 & 59.80 & 64.37 & 58.99 & 62.23 & 59.75 \\
\hline$>50$ & 33.19 & 35.62 & 28.91 & 39.48 & 31.67 & 32.07 \\
\hline \multicolumn{7}{|c|}{ Duration of unemployment in classes (in weeks) } \\
\hline$<13$ & 24.85 & 13.46 & 18.82 & 14.57 & 12.74 & 16.45 \\
\hline $13-52$ & 35.19 & 35.34 & 41.01 & 43.48 & 43.07 & 40.45 \\
\hline$>52$ & 39.96 & 51.20 & 40.17 & 41.95 & 44.19 & 43.10 \\
\hline
\end{tabular}

\footnotetext{
1 The programme duration is measured after the individual has left the programme.

${ }^{2} \mathrm{WC}=$ white-collar worker

3 The sector 'Other' consists of 'Forestry', 'Traffic Systems', 'Supplemental Construction' and 'Other'.
} 
Table A.3: Monthly and cumulated programme exits (in \%)

\begin{tabular}{|c|c|c|c|c|c|c|c|c|}
\hline \multirow[b]{3}{*}{ Month } & \multicolumn{4}{|c|}{ West-Germany } & \multicolumn{4}{|c|}{ East-Germany } \\
\hline & \multicolumn{2}{|c|}{ Men } & \multicolumn{2}{|c|}{ Women } & \multicolumn{2}{|c|}{ Men } & \multicolumn{2}{|c|}{ Women } \\
\hline & Monthly & Cumulated & Monthly & Cumulated & Monthly & Cumulated & Monthly & Cumulated \\
\hline Mar 00 & 2.97 & 2.97 & 2.58 & 2.58 & 1.16 & 1.16 & 0.83 & 0.83 \\
\hline Apr 00 & 5.14 & 8.11 & 3.83 & 6.41 & 2.00 & 3.16 & 1.19 & 2.02 \\
\hline May 00 & 6.82 & 14.93 & 3.65 & 10.06 & 3.02 & 6.18 & 1.70 & 3.72 \\
\hline Jun 00 & 5.89 & 20.82 & 3.74 & 13.80 & 2.55 & 8.73 & 1.54 & 5.26 \\
\hline Jul 00 & 4.87 & 25.69 & 3.74 & 17.54 & 2.14 & 10.87 & 1.05 & 6.31 \\
\hline Aug 00 & 6.16 & 31.85 & 7.56 & 25.10 & 5.54 & 16.41 & 5.09 & 11.40 \\
\hline Sep 00 & 4.52 & 36.37 & 4.89 & 29.99 & 2.58 & 18.99 & 1.66 & 13.06 \\
\hline Oct 00 & 5.36 & 41.73 & 4.18 & 34.17 & 5.37 & 24.36 & 2.22 & 15.28 \\
\hline Nov 00 & 5.14 & 46.87 & 4.98 & 39.15 & 3.70 & 28.06 & 2.95 & 18.23 \\
\hline Dec 00 & 4.87 & 51.74 & 3.56 & 42.71 & 1.97 & 30.03 & 1.56 & 19.79 \\
\hline Jan 01 & 5.18 & 56.92 & 4.27 & 46.98 & 1.05 & 31.08 & 0.79 & 20.58 \\
\hline Feb 01 & 34.65 & 91.57 & 39.41 & 86.39 & 62.42 & 93.50 & 72.51 & 93.09 \\
\hline Mar 01 & 1.46 & 93.03 & 1.78 & 88.17 & 3.84 & 97.34 & 4.22 & 97.31 \\
\hline Apr 01 & 0.31 & 93.34 & 0.18 & 88.35 & 0.00 & 97.34 & 0.06 & 97.37 \\
\hline May 01 & 0.62 & 93.96 & 1.16 & 89.51 & 0.41 & 97.75 & 0.24 & 97.61 \\
\hline Jun 01 & 0.27 & 94.23 & 0.44 & 89.95 & 0.00 & 97.75 & 0.04 & 97.65 \\
\hline Jul 01 & 0.49 & 94.72 & 0.71 & 90.66 & 0.07 & 97.82 & 0.04 & 97.69 \\
\hline Aug 01 & 0.58 & 95.30 & 0.18 & 90.84 & 0.10 & 97.92 & 0.14 & 97.83 \\
\hline Sep 01 & 0.22 & 95.52 & 0.44 & 91.28 & 0.10 & 98.02 & 0.00 & 97.83 \\
\hline Oct 01 & 0.13 & 95.65 & 0.09 & 91.37 & 0.00 & 98.02 & 0.02 & 97.85 \\
\hline Nov 01 & 0.27 & 95.92 & 0.27 & 91.64 & 0.07 & 98.09 & 0.06 & 97.91 \\
\hline Dec 01 & 0.62 & 96.54 & 0.36 & 92.00 & 0.00 & 98.09 & 0.02 & 97.93 \\
\hline Jan 02 & 0.18 & 96.72 & 0.53 & 92.53 & 0.00 & 98.09 & 0.02 & 97.95 \\
\hline Feb 02 & 1.95 & 98.67 & 6.85 & 99.38 & 1.60 & 99.69 & 1.66 & 99.61 \\
\hline Mar 02 & 0.09 & 98.76 & 0.09 & 99.47 & 0.17 & 99.87 & 0.08 & 99.69 \\
\hline
\end{tabular}

Table A.4: Matching Protocol for the estimation of $\theta_{0}^{m l}$

\begin{tabular}{|c|c|}
\hline Step & Description \\
\hline 1 & $\begin{array}{l}\text { Separate the treated individuals from the non-treated individuals and denote } \\
\text { the group of the treated individuals by } m \text {, the group of non-treated by } l \text {. Sep- } \\
\text { arate the group of treated individuals into five groups } m \in\{1, \ldots, 5\} \text {, according } \\
\text { to the type of treatment they received. }\end{array}$ \\
\hline 2 & $\begin{array}{l}\text { Take all individuals in } l \text { and the first group of individuals out of } m \text { and estimate } \\
P^{m \mid m l} \text {. Order the units in the treatment group randomly. }\end{array}$ \\
\hline 3 & Choose one unit out of the treatment group and delete it from the pool. \\
\hline 4 & $\begin{array}{l}\text { Find an individual in the subsample of individuals in } l \text { that is as close as } \\
\text { possible to the one chosen in } 3 \text { in terms of the estimated propensity score and } \\
\text { remove this observation. }\end{array}$ \\
\hline 5 & Repeat 3 and 4 until no participant in $m$ is left. \\
\hline 6 & Compute the conditional expectation of the matched comparison group. \\
\hline 7 & Go back to step 2 and repeat the steps $2-6$ for all $m$. \\
\hline 8 & $\begin{array}{l}\text { Compute the estimate of the treatment effects } \theta_{0}^{1 l}, \theta_{0}^{2 l}, \theta_{0}^{3 l}, \theta_{0}^{4 l} \text { and } \theta_{0}^{5 l} \text { using } \\
\text { the results of } 6 \text {. }\end{array}$ \\
\hline
\end{tabular}


Table A.5: Probit estimation results for men in West-Germany

\begin{tabular}{|c|c|c|c|c|c|}
\hline & Agriculture & $\begin{array}{l}\text { Constr. \& } \\
\text { Industry }\end{array}$ & $\begin{array}{l}\text { Office \& } \\
\text { Services }\end{array}$ & $\begin{array}{c}\text { Community } \\
\text { Services }\end{array}$ & Others \\
\hline & \multicolumn{5}{|c|}{ vs. Non Participation } \\
\hline Variable & Coeff. & Coeff. & Coeff. & Coeff. & Coeff. \\
\hline Constant & -2.1362 & -1.1336 & -5.4904 & -1.4569 & -1.9879 \\
\hline \multicolumn{6}{|l|}{ Socio-Demographic Variables } \\
\hline Age & 0.0011 & -0.0588 & 0.1187 & -0.0517 & -0.0283 \\
\hline $\mathrm{Age}^{2}$ & $-2.86 \mathrm{E}-05$ & 0.0006 & -0.0014 & 0.0005 & 0.0003 \\
\hline Married & -0.0919 & 0.0640 & -0.1436 & -0.1189 & -0.0997 \\
\hline Number of children & 0.0385 & 0.0088 & 0.0420 & 0.0420 & 0.0156 \\
\hline German & 0.1859 & 0.3127 & 0.1414 & 0.1441 & 0.1263 \\
\hline \multicolumn{6}{|l|}{ Health restrictions } \\
\hline no health restrictions & Ref. & Ref. & Ref. & Ref. & Ref. \\
\hline accepted $\mathrm{DoR}^{1}, 80 \%$ and over & 0.4261 & -0.2744 & 1.0743 & 0.3153 & 0.2827 \\
\hline accepted DoR, $50 \%$ to under $80 \%$ & 0.3385 & -0.0630 & 0.8938 & 0.4299 & 0.2685 \\
\hline accepted DoR, $30 \%$ to under $50 \%$ & 0.5768 & - & 0.7942 & 0.6356 & 0.4030 \\
\hline accepted DoR, $30 \%$ to under $50 \%$ no equalisation & 0.2177 & -0.0812 & 0.5755 & 0.1112 & -0.0155 \\
\hline remaining health restrictions & 0.0326 & -0.2155 & 0.1297 & -0.0027 & -0.0202 \\
\hline \multicolumn{6}{|l|}{ Qualification Variables } \\
\hline \multicolumn{6}{|l|}{ Professional training } \\
\hline without completed professional training, without CSE & Ref. & Ref. & -0.1987 & 0.1680 & 0.2933 \\
\hline without completed professional training, with CSE & -0.2404 & -0.1405 & -0.2378 & 0.0748 & 0.1562 \\
\hline Industrial training & -0.3635 & -0.4029 & Ref. & Ref. & Ref. \\
\hline Full-time vocational school & -0.8761 & -0.3305 & 0.1125 & 0.2148 & -0.1235 \\
\hline Technical school & -0.3956 & -0.7630 & 0.3869 & 0.4931 & 0.1175 \\
\hline Polytechnic & -0.4680 & & 0.3859 & 0.7472 & 0.3855 \\
\hline College/ University & -0.6130 & -0.7308 & 0.3423 & 0.5828 & 0.3444 \\
\hline \multicolumn{6}{|l|}{ Occupational group } \\
\hline plant cultivation, breeding, fishery & 0.3612 & 0.2311 & -0.2451 & -0.1867 & 0.1409 \\
\hline mining, mineral extraction & -0.0739 & 0.0533 & - & - & -0.3048 \\
\hline manufacturing & Ref. & 0.3186 & -0.3145 & -0.0503 & 0.1684 \\
\hline technical professions & -0.3619 & 0.1088 & 0.1024 & -0.3804 & -0.0994 \\
\hline service professions & -0.1275 & Ref. & Ref. & Ref. & Ref. \\
\hline other professions & 0.0612 & 0.2342 & - & -0.0952 & 0.2271 \\
\hline \multicolumn{6}{|l|}{ Professional rank } \\
\hline worker, not skilled worker & Ref. & Ref. & -0.1675 & -0.1642 & -0.0038 \\
\hline worker, skilled worker & -0.4108 & -0.2570 & -0.2505 & -0.2384 & -0.1289 \\
\hline white-collar worker, simple occupations & -0.3360 & -0.1932 & 0.1732 & 0.0845 & 0.0269 \\
\hline white-collar worker, advanced occupations & -0.0722 & -0.2577 & 0.3421 & 0.0787 & -0.0031 \\
\hline other & -0.1234 & -0.0484 & Ref. & Ref. & Ref. \\
\hline Qualification (with work experience) & 0.0840 & -0.0348 & 0.2408 & 0.1146 & 0.1921 \\
\hline \multicolumn{6}{|l|}{ Career Variables } \\
\hline Duration of unemployment (weeks) & 0.0000 & -0.0002 & -0.0003 & -0.0007 & -0.0003 \\
\hline Duration of last employment (months) & -0.0021 & -0.0010 & -0.0015 & -0.0013 & -0.0012 \\
\hline Number of placement propositions & 0.0257 & 0.0188 & 0.0237 & 0.0198 & 0.0249 \\
\hline Last contact to job center & -0.0090 & -0.0153 & 0.0436 & 0.0134 & 0.0039 \\
\hline Rehabilitation attendant & -0.0486 & 0.1397 & 0.0542 & 0.0386 & -0.2161 \\
\hline Placement restraints & -0.2163 & 0.0715 & -0.4175 & -0.0959 & -0.0306 \\
\hline \multicolumn{6}{|l|}{ Programme before unemployment } \\
\hline no further education or job-preparative programme & Ref. & Ref. & Ref. & Ref. & Ref. \\
\hline further education compl. successfully, cont. education & 0.0893 & 0.2039 & 0.1271 & 0.0338 & 0.0848 \\
\hline further education compl. successfully, voc. adjustment & 0.3363 & 0.4125 & -0.0594 & - & 0.3738 \\
\hline job-preparative measure & 0.3617 & 0.2956 & - & - & 0.0796 \\
\hline job creation scheme & 0.9458 & 1.1101 & 0.9000 & 0.9192 & 1.0393 \\
\hline rehabilitation measure & -0.0976 & -0.0651 & 0.1854 & -0.1974 & 0.1111 \\
\hline \multicolumn{6}{|l|}{ Regional Variables } \\
\hline \multicolumn{6}{|l|}{ Size of labour office district (labour force) } \\
\hline to 150.000 & Ref. & -0.0479 & 0.0647 & 0.1925 & -0.1409 \\
\hline 150.000 to under 250.000 & -0.0814 & Ref. & Ref. & Ref. & Ref. \\
\hline 250.000 to under 350.000 & -0.4063 & 0.1285 & -0.2426 & 0.0382 & 0.0480 \\
\hline 350.000 to under 450.000 & -0.1612 & -0.0264 & 0.0202 & 0.1708 & 0.0277 \\
\hline
\end{tabular}


Table A.5: continued

\begin{tabular}{|c|c|c|c|c|c|}
\hline & Agriculture & $\begin{array}{l}\text { Constr. \& } \\
\text { Industry }\end{array}$ & $\begin{array}{l}\text { Office \& } \\
\text { Services }\end{array}$ & $\begin{array}{l}\text { Community } \\
\text { Services }\end{array}$ & Others \\
\hline & \multicolumn{5}{|c|}{ vs. Non Participation } \\
\hline Variable & Coeff. & Coeff. & Coeff. & Coeff. & Coeff. \\
\hline 450.000 and over & -0.3101 & -0.2739 & -0.0522 & 0.1845 & -0.0010 \\
\hline \multicolumn{6}{|c|}{ Underemployment rate of labour office district (4. quarter 1999) } \\
\hline$<10 \%$ & Ref. & -0.3122 & Ref. & Ref. & Ref. \\
\hline $10 \%-12,5 \%$ & 0.1432 & -0.3673 & -0.1285 & -0.1713 & -0.0587 \\
\hline $12,5 \%-15 \%$ & 0.0523 & Ref. & -0.2173 & -0.3479 & -0.1116 \\
\hline$>15 \%$ & 0.0019 & -0.1849 & 0.1454 & -0.2088 & -0.2268 \\
\hline No. of observations ${ }^{2}$ & 540 & 393 & 136 & 349 & 859 \\
\hline
\end{tabular}

Bold letters indicate significance at the $1 \%$ level, Italic letters refer to the $5 \%$ level.

${ }^{1} \mathrm{DoR}=$ Degree of restriction

${ }^{2}$ No. of observations contains only participants. Corresponding no. of non-participants is 47,236 .

Ref.=Reference category for probit estimation

- Category has been omitted from estimation

Table A.6: Probit estimation results for women in West-Germany ${ }^{(a)}$

\begin{tabular}{|c|c|c|c|c|c|}
\hline & Agriculture & $\begin{array}{l}\text { Constr. \& } \\
\text { Industry }\end{array}$ & $\begin{array}{l}\text { Office \& } \\
\text { Services }\end{array}$ & $\begin{array}{c}\text { Community } \\
\text { Services }\end{array}$ & Others \\
\hline & \multicolumn{5}{|c|}{ vs. Non Participation } \\
\hline Variable & Coeff. & Coeff. & Coeff. & Coeff. & Coeff. \\
\hline Constant & & & -3.4513 & -2.3926 & -1.5896 \\
\hline \multicolumn{6}{|l|}{ Socio-Demographic Variables } \\
\hline Age & & & 0.0454 & -0.0181 & -0.0252 \\
\hline $\mathrm{Age}^{2}$ & & & -0.0006 & 0.0001 & 0.0002 \\
\hline Married & & & -0.0296 & -0.2047 & -0.2026 \\
\hline Number of children & & & -0.0215 & 0.0389 & -0.0352 \\
\hline German & & & 0.1121 & 0.1159 & 0.0946 \\
\hline \multicolumn{6}{|l|}{ Health restrictions } \\
\hline no health restrictions & & & Ref. & Ref. & Ref. \\
\hline accepted DoR ${ }^{1}, 80 \%$ and over & & & 0.7754 & 0.5711 & 0.4369 \\
\hline accepted DoR, $50 \%$ to under $80 \%$ & & & 0.5151 & 0.0872 & 0.2998 \\
\hline accepted DoR, $30 \%$ to under $50 \%$ & & & 1.0982 & 0.7195 & 0.8150 \\
\hline accepted DoR, $30 \%$ to under $50 \%$ no equalisation & & & -0.0432 & 0.0301 & -0.0229 \\
\hline remaining health restrictions & & & -0.1788 & 0.0012 & -0.0726 \\
\hline \multicolumn{6}{|l|}{ Qualification Variables } \\
\hline \multicolumn{6}{|l|}{ Professional training } \\
\hline without completed professional training, without CSE & & & -0.5191 & 0.0635 & 0.0858 \\
\hline without completed professional training, with CSE & & & 0.0245 & 0.1650 & 0.1080 \\
\hline industrial training & & & Ref. & Ref. & Ref. \\
\hline Full-time vocational school & & & -0.1043 & 0.1197 & -0.0871 \\
\hline Technical school & & & -0.0175 & 0.4850 & 0.1860 \\
\hline Polytechnic & & & 0.4115 & 0.8784 & 0.6011 \\
\hline College/ University & & & 0.5070 & 0.4027 & 0.4930 \\
\hline \multicolumn{6}{|l|}{ Occupational group } \\
\hline plant cultivation, breeding, fishery & & & - & -0.1635 & 0.2318 \\
\hline mining, mineral extraction & & & - & - & - \\
\hline manufacturing & & & -0.5789 & Ref. & 0.1733 \\
\hline technical professions & & & 0.1588 & -0.6313 & 0.0816 \\
\hline service professions & & & Ref. & 0.2679 & Ref. \\
\hline other professions & & & 0.3406 & 0.1832 & 0.2094 \\
\hline \multicolumn{6}{|l|}{ Professional rank } \\
\hline worker, not skilled worker & & & -0.3465 & 0.0379 & -0.0857 \\
\hline worker, skilled worker & & & -0.2474 & -0.0736 & -0.2119 \\
\hline white-collar worker, simple occupations & & & Ref. & 0.0603 & -0.1544 \\
\hline white-collar worker, advanced occupations & & & -0.1232 & 0.3136 & 0.0288 \\
\hline other & & & -0.1265 & Ref. & Ref. \\
\hline Qualification (with work experience) & & & 0.1698 & 0.1013 & -0.0022 \\
\hline \multicolumn{6}{|l|}{ Career Variables } \\
\hline Duration of unemployment (weeks) & & & -0.0012 & -0.0007 & -0.0003 \\
\hline
\end{tabular}


Table A.6: continued

\begin{tabular}{|c|c|c|c|c|c|}
\hline & Agriculture & $\begin{array}{l}\text { Constr. \& } \\
\text { Industry }\end{array}$ & $\begin{array}{l}\text { Office \& } \\
\text { Services }\end{array}$ & $\begin{array}{l}\text { Community } \\
\text { Services }\end{array}$ & Others \\
\hline & \multicolumn{5}{|c|}{ vs. Non Participation } \\
\hline Variable & Coeff. & Coeff. & Coeff. & Coeff. & Coeff. \\
\hline Duration of last employment (months) & & & -0.0002 & -0.0011 & -0.0014 \\
\hline Number of placement propositions & & & 0.0296 & 0.0213 & 0.0250 \\
\hline Last contact to job center & & & 0.0248 & 0.0329 & -0.0163 \\
\hline Rehabilitation attendant & & & -0.0487 & 0.0624 & 0.3013 \\
\hline Placement restraints & & & -0.1253 & -0.0848 & -0.1797 \\
\hline \multicolumn{6}{|l|}{ Programme before unemployment } \\
\hline no further education or job-preparative programme & & & Ref. & Ref. & Ref. \\
\hline further education compl. successfully, cont. education & & & 0.4274 & 0.2386 & 0.0607 \\
\hline further education compl. successfully, voc. adjustment & & & 0.3168 & 0.0998 & 0.3932 \\
\hline job-preparative measure & & & - & 1.4814 & 0.5991 \\
\hline job creation scheme & & & 1.4912 & 1.5696 & 1.2716 \\
\hline rehabilitation measure & & & 1.0426 & 0.1966 & 0.1056 \\
\hline \multicolumn{6}{|l|}{ Regional Variables } \\
\hline \multicolumn{6}{|l|}{ Size of labour office district (labour force) } \\
\hline to 150.000 & & & -0.0896 & 0.0156 & -0.2729 \\
\hline 150.000 to under 250.000 & & & Ref. & Ref. & -0.1738 \\
\hline 250.000 to under 350.000 & & & -0.2225 & 0.1778 & -0.1265 \\
\hline 350.000 to under 450.000 & & & -0.2594 & 0.1901 & -0.2658 \\
\hline 450.000 and over & & & -0.0775 & 0.0323 & Ref. \\
\hline \multicolumn{6}{|c|}{ Underemployment rate of labour office district (4. quarter 1999) } \\
\hline$<10 \%$ & & & Ref. & Ref. & Ref. \\
\hline $10 \%-12,5 \%$ & & & -0.0885 & 0.1159 & -0.2358 \\
\hline $12,5 \%-15 \%$ & & & -0.1400 & -0.1519 & -0.0604 \\
\hline$>15 \%$ & & & -0.3618 & -0.0509 & -0.3034 \\
\hline No. of observations ${ }^{2}$ & & & 212 & 535 & 239 \\
\hline
\end{tabular}

(a) Due to the small number of participants the sectors agriculture and construction \& industry have been omitted.

Bold letters indicate significance at the $1 \%$ level, Italic letters refer to the $5 \%$ level.

${ }^{1}$ DoR=Degree of restriction

2 No. of observations contains only participants. Corresponding no. of non-participants is 37,959

Ref.=Reference category for probit estimation

- Category has been omitted from estimation 
Table A.7: Probit estimation results for men in East-Germany

\begin{tabular}{|c|c|c|c|c|c|}
\hline & Agriculture & $\begin{array}{l}\text { Constr. \& } \\
\text { Industry }\end{array}$ & $\begin{array}{l}\text { Office \& } \\
\text { Services }\end{array}$ & $\begin{array}{l}\text { Community } \\
\text { Services }\end{array}$ & Others \\
\hline & \multicolumn{5}{|c|}{ vs. Non Participation } \\
\hline Variable & Coeff. & Coeff. & Coeff. & Coeff. & Coeff. \\
\hline Constant & -3.6252 & -3.6638 & -5.0056 & -3.2208 & -2.7295 \\
\hline \multicolumn{6}{|l|}{ Socio-Demographic Variables } \\
\hline Age & 0.0481 & 0.0574 & 0.0824 & 0.0068 & 0.0157 \\
\hline $\mathrm{Age}^{2}$ & -0.0004 & -0.0006 & -0.0008 & -0.0001 & -0.0001 \\
\hline Married & 0.0677 & 0.0803 & 0.2413 & 0.2496 & 0.0392 \\
\hline Number of children & -0.0039 & -0.0170 & -0.0402 & -0.0487 & 0.0038 \\
\hline German & 0.3558 & 0.3317 & - & 0.2459 & 0.2545 \\
\hline \multicolumn{6}{|l|}{ Health restrictions } \\
\hline no health restrictions & Ref. & Ref. & Ref. & Ref. & Ref. \\
\hline accepted DoR ${ }^{1}, 80 \%$ and over & 0.3524 & - & 0.3396 & 0.4010 & 0.1020 \\
\hline accepted DoR, $50 \%$ to under $80 \%$ & 0.0605 & 0.1603 & 0.4490 & 0.2706 & 0.2921 \\
\hline accepted DoR, $30 \%$ to under $50 \%$ & 0.0249 & 0.3366 & 0.3164 & 0.4002 & 0.3459 \\
\hline accepted DoR, $30 \%$ to under $50 \%$ no equalisation & 0.0961 & -0.0341 & 0.2099 & 0.0484 & -0.2111 \\
\hline remaining health restrictions & -0.0535 & -0.0043 & -0.1452 & -0.0294 & -0.0346 \\
\hline \multicolumn{6}{|l|}{ Qualification Variables } \\
\hline \multicolumn{6}{|l|}{ Professional training } \\
\hline without completed professional training, without CSE & 0.1844 & 0.0766 & -0.2373 & -0.1303 & 0.0732 \\
\hline without completed professional training, with CSE & 0.1317 & 0.0513 & 0.0133 & 0.0487 & 0.1841 \\
\hline Industrial training & Ref. & Ref. & Ref. & Ref. & Ref. \\
\hline Full-time vocational school & -0.2414 & - & 0.1168 & 0.2836 & 0.0237 \\
\hline Technical school & -0.0973 & -0.3702 & 0.5314 & 0.2402 & 0.1883 \\
\hline Polytechnic & -0.3764 & -0.1381 & 0.2445 & 0.3508 & 0.0775 \\
\hline College/ University & -0.2791 & -0.7474 & 0.3577 & 0.2957 & 0.1271 \\
\hline \multicolumn{6}{|l|}{ Occupational group } \\
\hline plant cultivation, breeding, fishery & 0.1609 & -0.1701 & -0.2881 & -0.3725 & -0.0765 \\
\hline mining, mineral extraction & -0.0371 & - & - & - & -0.3469 \\
\hline manufacturing & Ref. & Ref. & -0.5333 & -0.1176 & Ref. \\
\hline technical professions & -0.2018 & -0.2644 & 0.2360 & -0.1024 & -0.1456 \\
\hline service professions & -0.1570 & -0.3038 & Ref. & Ref. & -0.0472 \\
\hline other professions & -0.2553 & -0.8850 & - & -0.3939 & -0.3892 \\
\hline \multicolumn{6}{|l|}{ Professional rank } \\
\hline worker, not skilled worker & Ref. & -0.0006 & -0.0468 & Ref. & 0.1009 \\
\hline worker, skilled worker & -0.1485 & -0.1313 & -0.0351 & 0.0674 & Ref. \\
\hline white-collar worker, simple occupations & -0.2129 & 0.0305 & 0.2165 & 0.2101 & 0.2129 \\
\hline white-collar worker, advanced occupations & -0.1219 & 0.0697 & -0.0061 & 0.2941 & -0.2612 \\
\hline other & -0.0016 & Ref. & Ref. & 0.1325 & 0.1187 \\
\hline Qualification (with work experience) & -0.0493 & -0.0244 & 0.2347 & 0.1917 & 0.1580 \\
\hline \multicolumn{6}{|l|}{ Career Variables } \\
\hline Duration of unemployment (weeks) & $1.52 \mathrm{E}-05$ & -0.0003 & -0.0011 & -0.0009 & -0.0004 \\
\hline Duration of last employment (months) & -0.0010 & -0.0013 & -0.0016 & -0.0018 & -0.0012 \\
\hline Number of placement propositions & 0.0237 & 0.0296 & 0.0364 & 0.0259 & 0.0308 \\
\hline Last contact to job center & -0.0420 & -0.0417 & -0.0210 & -0.0141 & -0.0482 \\
\hline Rehabilitation attendant & 0.0325 & 0.0810 & 0.0911 & 0.3556 & 0.1241 \\
\hline Placement restraints & -0.1402 & -0.1884 & -0.0871 & -0.0619 & -0.1427 \\
\hline \multicolumn{6}{|l|}{ Programme before unemployment } \\
\hline no further education or job-preparative programme & Ref. & Ref. & Ref. & Ref. & Ref. \\
\hline further education compl. successfully, cont. education & 0.2270 & 0.2069 & 0.4175 & 0.1849 & 0.1434 \\
\hline further education compl. successfully, voc. adjustment & 0.3206 & 0.3279 & 0.1198 & 0.3940 & 0.3005 \\
\hline job-preparative measure & - & 0.6743 & - & 0.6923 & 0.1349 \\
\hline job creation scheme & 0.7968 & 0.7235 & 0.6202 & 0.8904 & 0.8237 \\
\hline rehabilitation measure & - & 0.1073 & 0.4903 & 0.0732 & 0.3017 \\
\hline \multicolumn{6}{|l|}{ Regional Variables } \\
\hline \multicolumn{6}{|l|}{ Size of labour office district (labour force) } \\
\hline to 150.000 & -0.0938 & Ref. & Ref. & -0.0705 & -0.8443 \\
\hline 150.000 to under 250.000 & Ref. & -0.3956 & -0.2123 & Ref. & -0.5855 \\
\hline 250.000 to under 350.000 & -0.1225 & -0.5321 & -0.1230 & -0.0893 & -0.4153 \\
\hline 350.000 to under 450.000 & -0.3225 & - & -0.5979 & -0.3445 & Ref. \\
\hline
\end{tabular}


Table A.7: continued

\begin{tabular}{|c|c|c|c|c|c|}
\hline & Agriculture & $\begin{array}{l}\text { Constr. \& } \\
\text { Industry }\end{array}$ & $\begin{array}{l}\text { Office \& } \\
\text { Services }\end{array}$ & $\begin{array}{l}\text { Community } \\
\text { Services }\end{array}$ & Others \\
\hline & \multicolumn{5}{|c|}{ vs. Non Participation } \\
\hline Variable & Coeff. & Coeff. & Coeff. & Coeff. & Coeff. \\
\hline 450.000 and over & - & - & - & - & - \\
\hline \multicolumn{6}{|c|}{ Underemployment rate of labour office district (4. quarter 1999) } \\
\hline$<20 \%$ & -0.5478 & 0.3090 & & -0.0310 & 0.2031 \\
\hline $20 \%-22,5 \%$ & -0.2194 & -0.0387 & 0.2270 & -0.1530 & -0.2433 \\
\hline $22,5 \%-25 \%$ & -0.2535 & -0.0535 & Ref. & 0.0131 & -0.0481 \\
\hline $25 \%-27,5 \%$ & -0.2514 & -0.0635 & 0.0589 & -0.0052 & -0.2971 \\
\hline $27,5 \%-30 \%$ & -0.0676 & Ref. & 0.1779 & Ref. & Ref. \\
\hline$>30 \%$ & Ref. & -0.2826 & 0.0795 & -0.3190 & -0.0517 \\
\hline No. of observations ${ }^{2}$ & 870 & 407 & 202 & 414 & 1,050 \\
\hline
\end{tabular}

Bold letters indicate significance at the $1 \%$ level, Italic letters refer to the $5 \%$ level.

${ }^{1}$ DoR=Degree of restriction

${ }^{2}$ No. of observations contains only participants. Corresponding no. of non-participants is 67,187 .

Ref.=Reference category for probit estimation

- Category has been omitted from estimation

Table A.8: Probit estimation results for women in East-Germany

\begin{tabular}{|c|c|c|c|c|c|}
\hline & Agriculture & $\begin{array}{l}\text { Constr. \& } \\
\text { Industry }\end{array}$ & $\begin{array}{l}\text { Office \& } \\
\text { Services }\end{array}$ & $\begin{array}{l}\text { Community } \\
\text { Services }\end{array}$ & Others \\
\hline & \multicolumn{5}{|c|}{ vs. Non Participation } \\
\hline Variable & Coeff. & Coeff. & Coeff. & Coeff. & Coeff. \\
\hline Constant & -4.1795 & -3.2795 & -5.5024 & -4.4953 & -4.0081 \\
\hline \multicolumn{6}{|l|}{ Socio-Demographic Variables } \\
\hline Age & 0.0679 & 0.0296 & 0.1066 & 0.0758 & 0.0540 \\
\hline $\mathrm{Age}^{2}$ & -0.0008 & -0.0003 & -0.0012 & -0.0008 & -0.0006 \\
\hline Married & 0.0534 & 0.0282 & 0.1166 & 0.0696 & -0.0231 \\
\hline Number of children & 0.0050 & 0.0149 & -0.0163 & -0.0173 & -0.0020 \\
\hline German & 0.5349 & 0.0433 & 0.5262 & 0.5384 & 0.3211 \\
\hline \multicolumn{6}{|l|}{ Health restrictions } \\
\hline no health restrictions & Ref. & Ref. & Ref. & Ref. & Ref. \\
\hline accepted DoR ${ }^{1}, 80 \%$ and over & 0.2830 & 0.3897 & 0.0667 & 0.5334 & 0.5591 \\
\hline accepted DoR, $50 \%$ to under $80 \%$ & -0.1553 & - & 0.5632 & 0.2311 & 0.2289 \\
\hline accepted DoR, $30 \%$ to under $50 \%$ & -0.0858 & 0.1180 & 0.3681 & 0.3958 & 0.3179 \\
\hline accepted DoR, $30 \%$ to under $50 \%$ no equalisation & -0.1120 & - & -0.1083 & 0.1608 & -0.2554 \\
\hline remaining health restrictions & -0.1357 & -0.0631 & 0.0153 & -0.0536 & -0.0046 \\
\hline \multicolumn{6}{|l|}{ Qualification Variables } \\
\hline \multicolumn{6}{|l|}{ Professional training } \\
\hline without completed professional training, without CSE & 0.1310 & 0.1566 & -0.9507 & -0.4526 & -0.1225 \\
\hline without completed professional training, with CSE & 0.0443 & -0.0781 & -0.1132 & -0.0012 & 0.0456 \\
\hline Industrial training & Ref. & Ref. & Ref. & Ref. & Ref. \\
\hline Full-time vocational school & 0.0963 & -0.0030 & 0.1683 & 0.3450 & 0.1373 \\
\hline Technical school & -0.2693 & -0.2176 & 0.2911 & 0.3781 & 0.3035 \\
\hline Polytechnic & 0.1360 & - & 0.5345 & 0.2683 & 0.1850 \\
\hline College/ University & -0.1583 & - & 0.4612 & 0.1375 & 0.2337 \\
\hline \multicolumn{6}{|l|}{ Occupational group } \\
\hline plant cultivation, breeding, fishery & 0.5078 & 0.3728 & -0.3318 & -0.3692 & 0.0890 \\
\hline mining, mineral extraction & - & - & - & - & - \\
\hline manufacturing & 0.2565 & 0.1826 & -0.6076 & -0.1589 & 0.1069 \\
\hline technical professions & 0.1402 & 0.1712 & 0.1851 & -0.1560 & 0.2544 \\
\hline service professions & Ref. & Ref. & Ref. & Ref. & Ref. \\
\hline other professions & -0.4788 & -0.1391 & & -0.3788 & -0.2937 \\
\hline \multicolumn{6}{|l|}{ Professional rank } \\
\hline worker, not skilled worker & Ref. & Ref. & -0.2871 & Ref. & Ref. \\
\hline worker, skilled worker & -0.1744 & -0.1306 & Ref. & 0.0811 & 0.0113 \\
\hline white-collar worker, simple occupations & -0.3843 & -0.1801 & 0.0799 & 0.1530 & 0.1451 \\
\hline white-collar worker, advanced occupations & -0.1637 & & 0.1199 & 0.1190 & -0.0234 \\
\hline other & -0.0410 & -0.1515 & -0.0228 & 0.0451 & 0.0646 \\
\hline
\end{tabular}


Table A.8: continued

\begin{tabular}{|c|c|c|c|c|c|}
\hline & Agriculture & $\begin{array}{l}\text { Constr. \& } \\
\text { Industry }\end{array}$ & $\begin{array}{l}\text { Office \& } \\
\text { Services }\end{array}$ & $\begin{array}{c}\text { Community } \\
\text { Services }\end{array}$ & Others \\
\hline & \multicolumn{5}{|c|}{ vs. Non Participation } \\
\hline Variable & Coeff. & Coeff. & Coeff. & Coeff. & Coeff. \\
\hline Qualification (with work experience) & 0.0117 & -0.1296 & -0.0308 & 0.0607 & 0.0825 \\
\hline \multicolumn{6}{|l|}{ Career Variables } \\
\hline Duration of unemployment (weeks) & -0.0004 & -0.0008 & -0.0016 & -0.0014 & -0.0012 \\
\hline Duration of last employment (months) & -0.0010 & -0.0011 & -0.0005 & -0.0008 & -0.0010 \\
\hline Number of placement propositions & 0.0318 & 0.0416 & 0.0452 & 0.0451 & 0.0433 \\
\hline Last contact to job center & -0.0268 & -0.0408 & -0.0198 & -0.0234 & -0.0211 \\
\hline Rehabilitation attendant & -0.1187 & 0.1562 & 0.0859 & 0.1660 & 0.0570 \\
\hline Placement restraints & -0.1407 & -0.0177 & -0.2287 & -0.0542 & -0.1378 \\
\hline \multicolumn{6}{|l|}{ Programme before unemployment } \\
\hline no further education or job-preparative programme & Ref. & Ref. & Ref. & Ref. & Ref. \\
\hline further education compl. successfully, cont. education & 0.1049 & -0.0038 & 0.3727 & 0.2580 & 0.1801 \\
\hline further education compl. successfully, voc. adjustment & 0.2719 & 0.2183 & 0.2752 & 0.2098 & 0.1957 \\
\hline job-preparative measure & 0.3043 & - & - & 0.4073 & - \\
\hline job creation scheme & 0.5608 & 0.3726 & 0.7931 & 0.7380 & 0.7204 \\
\hline rehabilitation measure & 0.2969 & & 0.2886 & 0.1495 & 0.0510 \\
\hline \multicolumn{6}{|l|}{ Regional Variables } \\
\hline \multicolumn{6}{|l|}{ Size of labour office district (labour force) } \\
\hline to 150.000 & -0.0398 & Ref. & 0.2690 & Ref. & Ref. \\
\hline 150.000 to under 250.000 & Ref. & -0.6235 & Ref. & 0.0364 & 0.1357 \\
\hline 250.000 to under 350.000 & -0.0972 & -0.1615 & 0.1981 & -0.0097 & 0.3104 \\
\hline 350.000 to under 450.000 & -0.2541 & -0.9115 & -0.5440 & -0.4799 & 0.5514 \\
\hline 450.000 and over & - & - & - & - & - \\
\hline \multicolumn{6}{|c|}{ Underemployment rate of labour office district (4. quarter 1999) } \\
\hline$<20 \%$ & -0.4675 & 0.1198 & -0.3689 & 0.2453 & -0.0372 \\
\hline $20 \%-22,5 \%$ & -0.3045 & 0.3653 & 0.1476 & 0.0003 & -0.0116 \\
\hline $22,5 \%-25 \%$ & -0.2429 & 0.0075 & 0.0258 & 0.1069 & -0.0912 \\
\hline $25 \%-27,5 \%$ & -0.1725 & 0.4083 & -0.0272 & 0.1206 & -0.0720 \\
\hline $27,5 \%-30 \%$ & -0.1068 & Ref. & Ref. & Ref. & Ref. \\
\hline$>30 \%$ & Ref. & 0.3828 & -0.0293 & 0.0884 & -0.0656 \\
\hline No. of observations ${ }^{2}$ & 921 & 188 & 649 & 1,815 & 1,479 \\
\hline
\end{tabular}

Bold letters indicate significance at the $1 \%$ level, Italic letters refer to the $5 \%$ level.

${ }^{1}$ DoR=Degree of restriction

2 No. of observations contains only participants. Corresponding no. of non-participants is 80,017 .

Ref. $=$ Reference category for probit estimation

- Category has been omitted from estimation 


\section{B Figures}

Figure B.1: Success Probabilities for Women in West Germany

(Lower and Upper Bounds, with 95\% confidence levels)
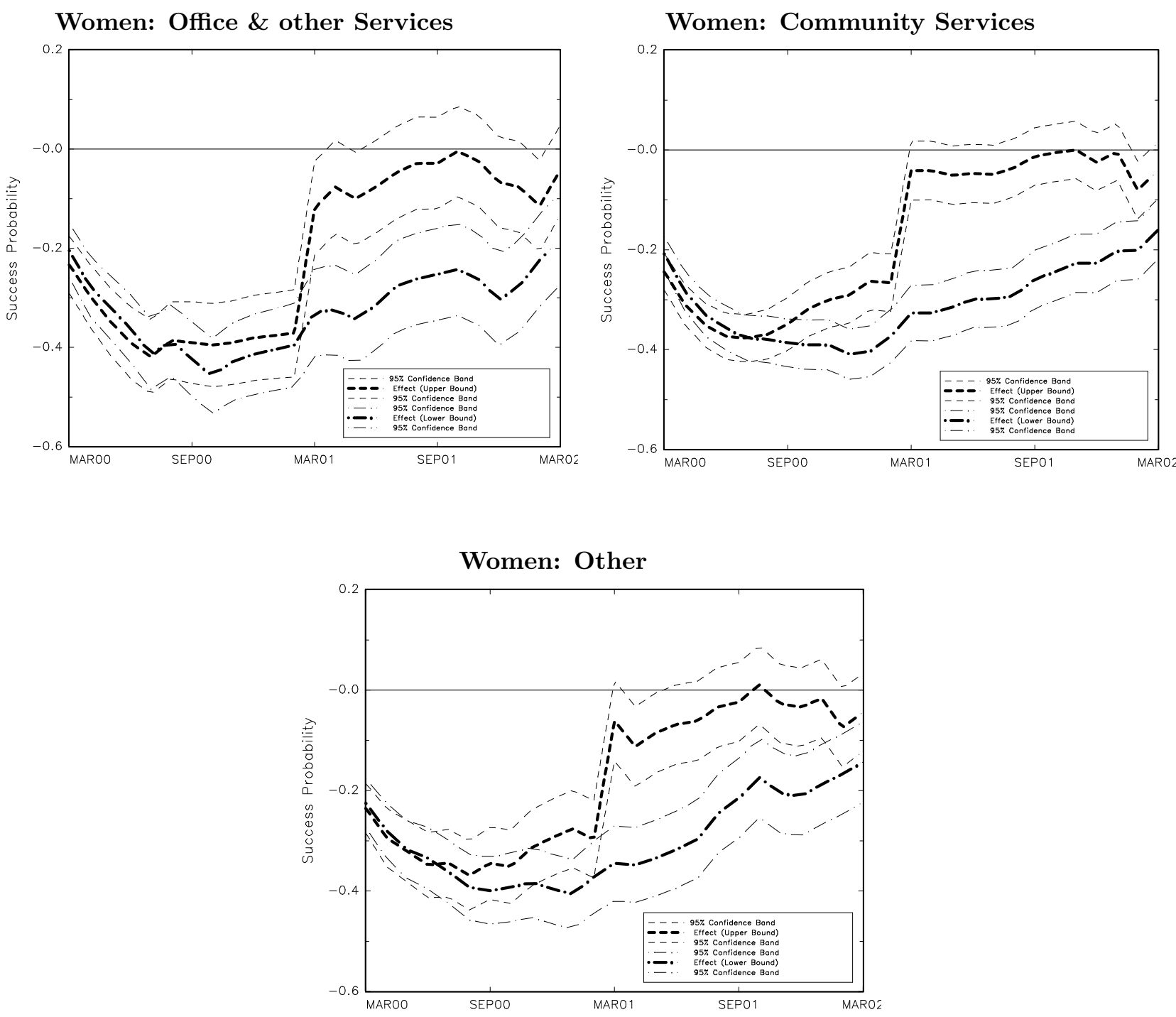
Figure B.2: Success Probabilities for Men in West Germany

(Lower and Upper Bounds, with 95\% confidence levels)

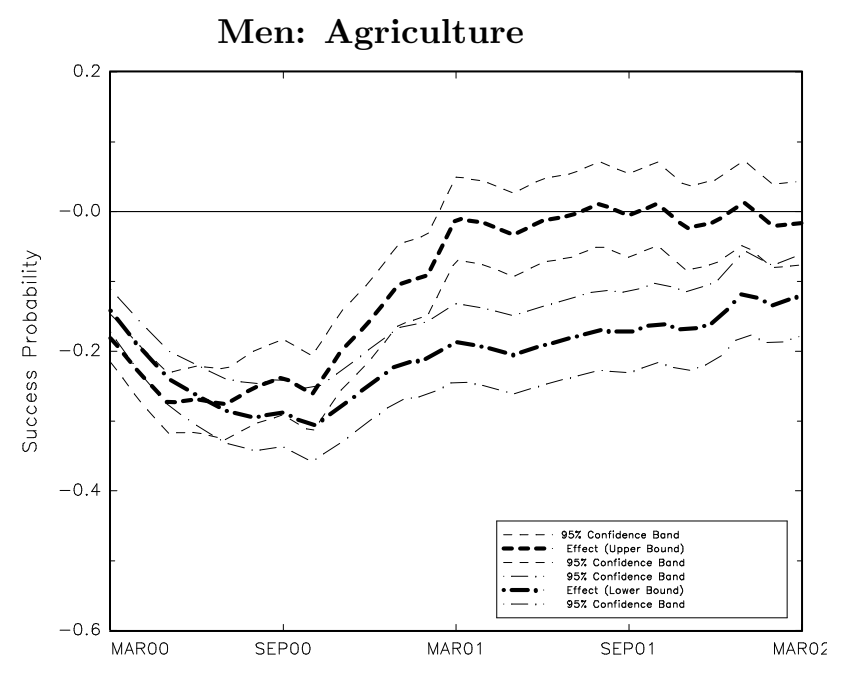

Men: Construction \& Industry

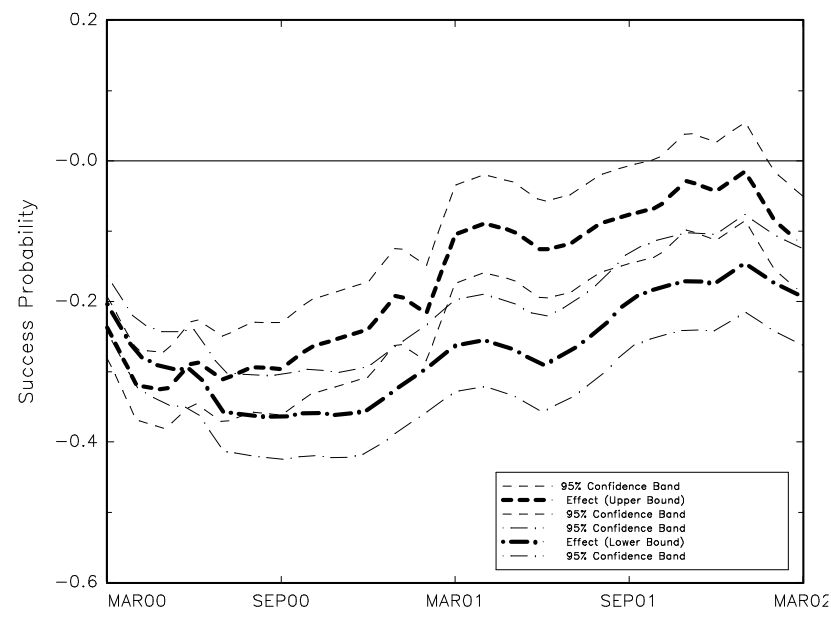

Men: Office \& other Services
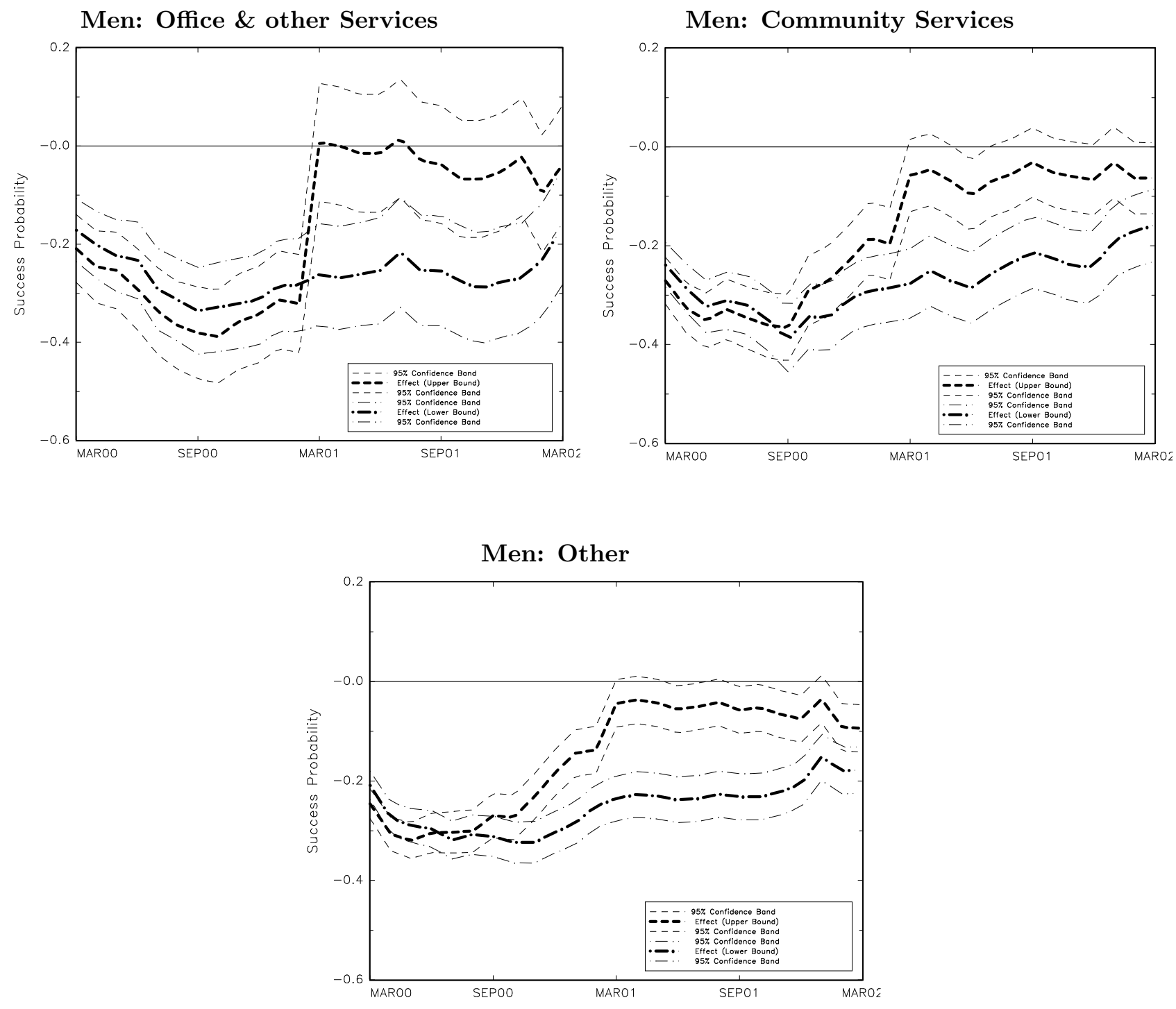
Figure B.3: Success Probabilities for Women in East Germany (Lower and Upper Bounds, with 95\% confidence levels)
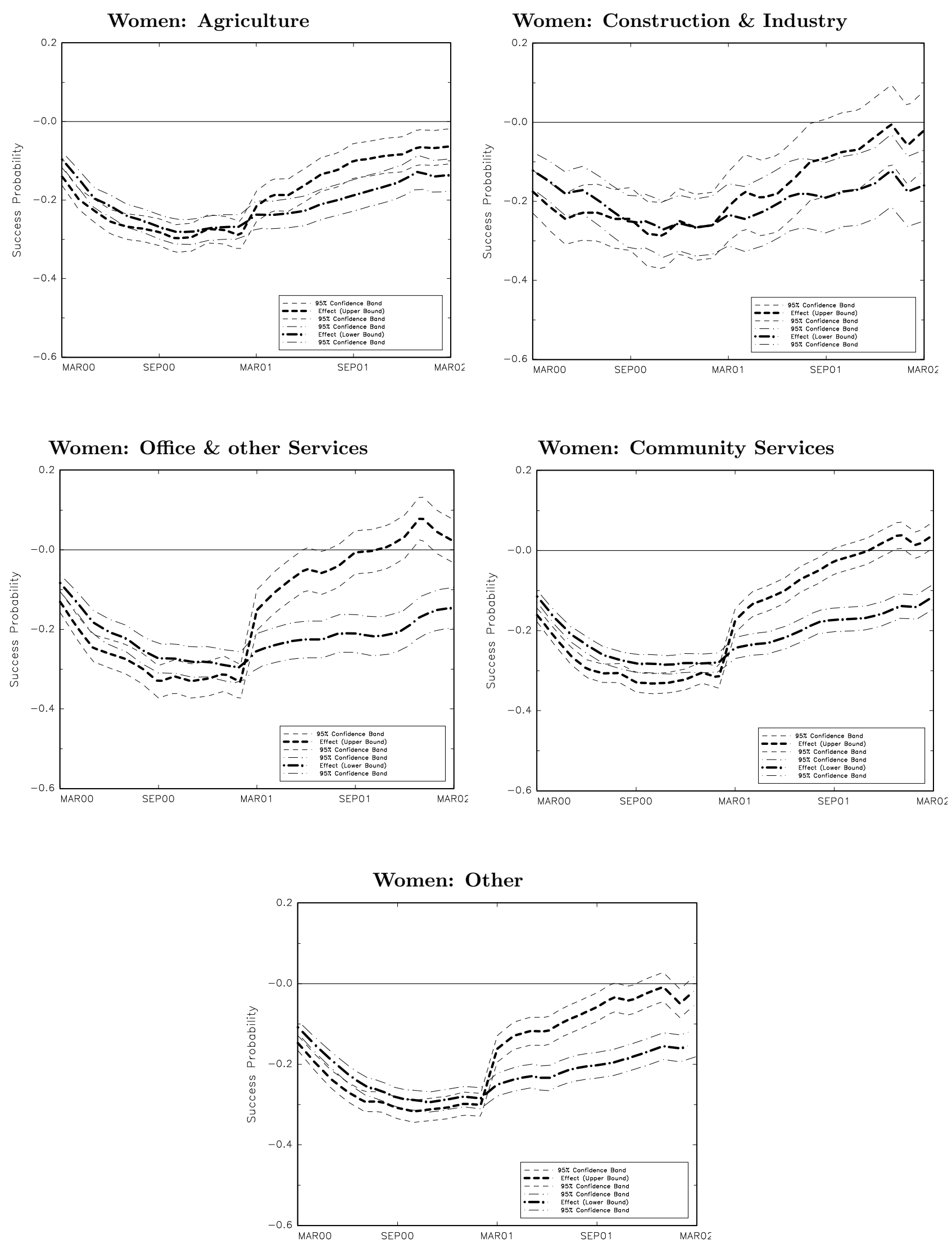
Figure B.4: Success Probabilities for Men in East Germany (Lower and Upper Bounds, with 95\% confidence levels)

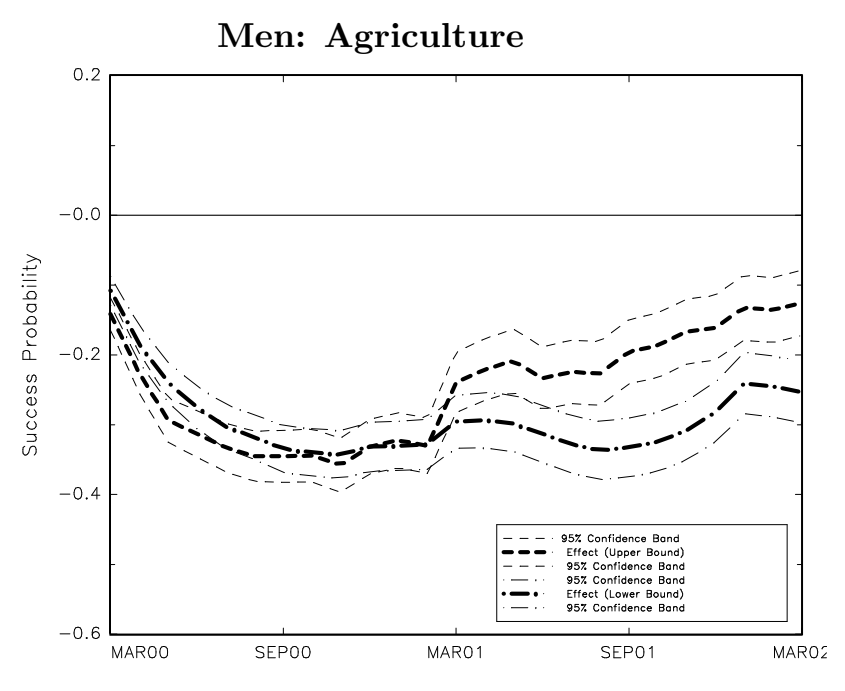

Men: Construction \& Industry

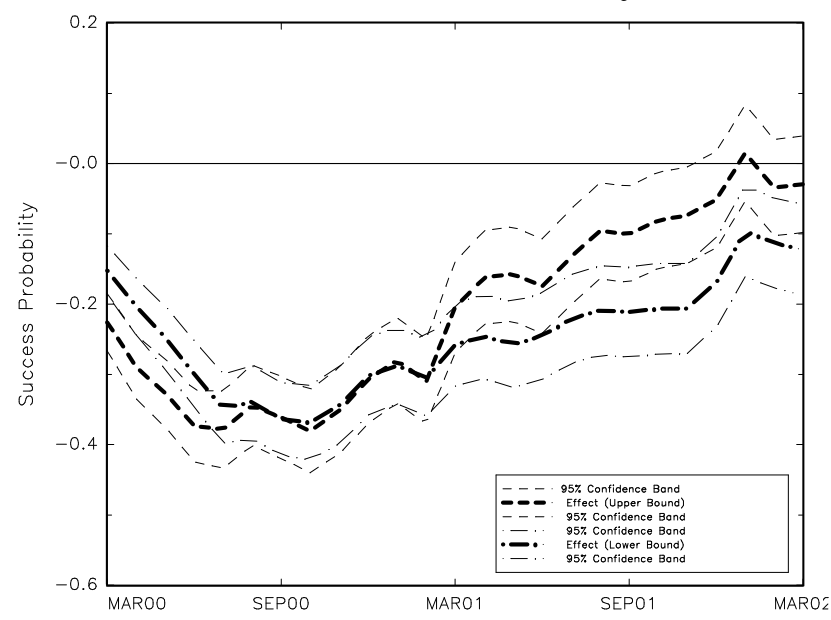

Men: Office \& other Services
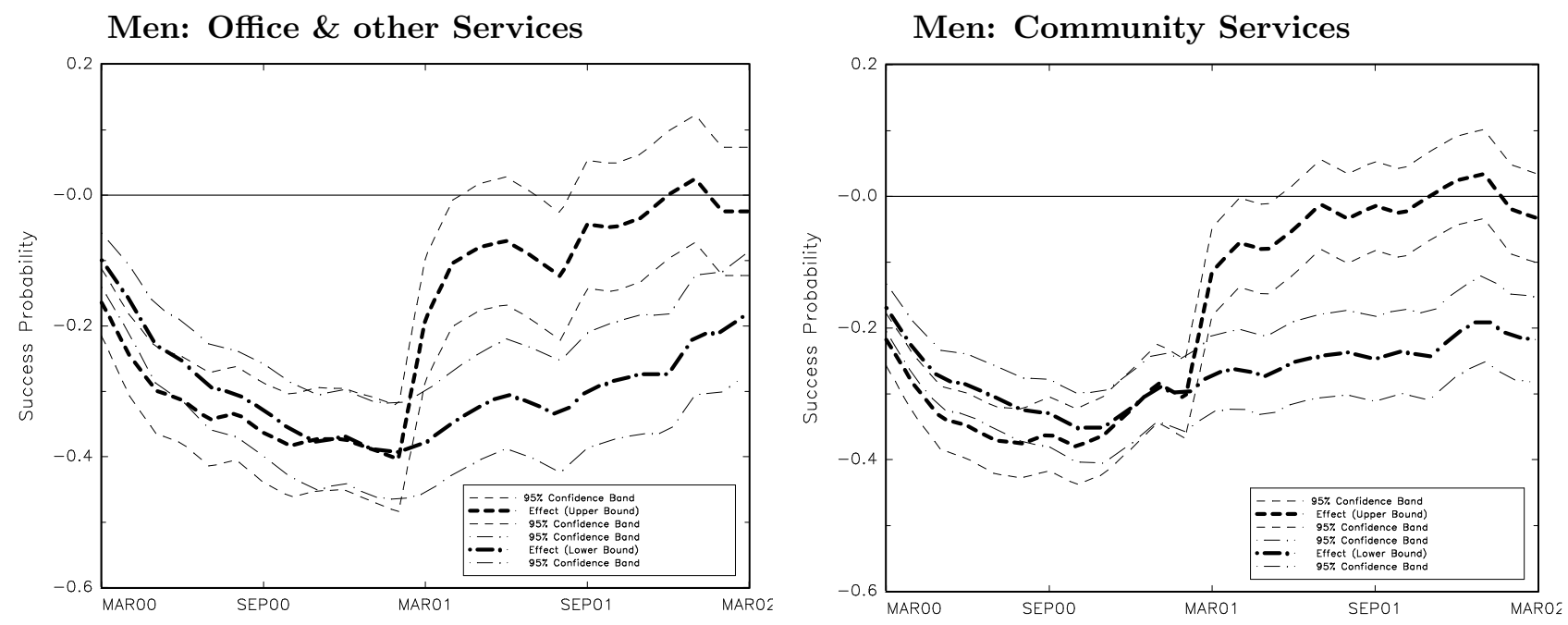

Men: Other

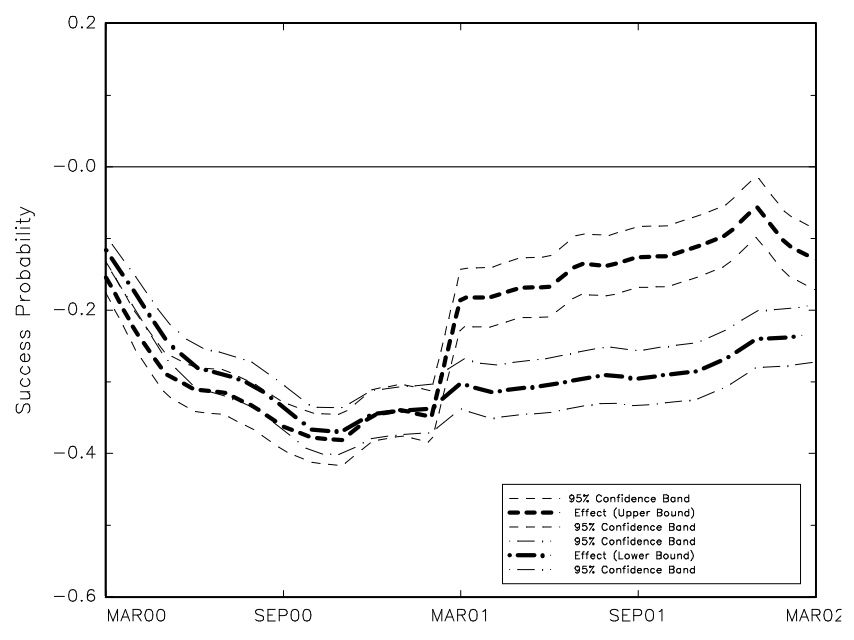

